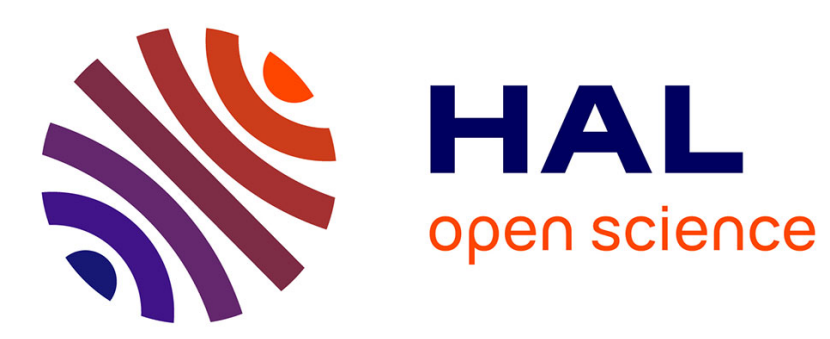

\title{
Trip-timing decisions and congestion with household scheduling preferences
}

\author{
André de Palma, Robin Lindsey, Nathalie Picard
}

\section{To cite this version:}

André de Palma, Robin Lindsey, Nathalie Picard. Trip-timing decisions and congestion with household scheduling preferences. 2015. hal-01104868

\section{HAL Id: hal-01104868 \\ https://hal.science/hal-01104868}

Preprint submitted on 19 Jan 2015

HAL is a multi-disciplinary open access archive for the deposit and dissemination of scientific research documents, whether they are published or not. The documents may come from teaching and research institutions in France or abroad, or from public or private research centers.
L'archive ouverte pluridisciplinaire HAL, est destinée au dépôt et à la diffusion de documents scientifiques de niveau recherche, publiés ou non, émanant des établissements d'enseignement et de recherche français ou étrangers, des laboratoires publics ou privés. 


\title{
TRIP-TIMING DECISIONS AND CONGESTION WITH HOUSEHOLD SCHEDULING PREFERENCES
}

\author{
André de PALMA \\ Robin LINDSEY \\ Nathalie PICARD
}

December 2014

Cahier $n^{\circ}$ 2015-01

\section{DEPARTEMENT D'ECONOMIE}

Route de Saclay

91128 PALAISEAU CEDEX

(33) 169333033

http://www.economie.polytechnique.edu/

mailto:chantal.poujouly@polytechnique.edu 


\title{
Trip-timing decisions and congestion with household scheduling preferences
}

\author{
André de Palma, ${ }^{*}$ Robin Lindsey ${ }^{\dagger}$ and Nathalie Picard ${ }^{\ddagger}$
}

December 22, 2014.

\begin{abstract}
Most traffic congestion models assume that agents make trip-timing decisions independently and receive payoffs at the origin and destination that do not depend on whether other agents are present. We depart from this paradigm by considering a variant of Vickrey's bottleneck model of the morning commute in which individuals live as couples and value time at home more when together than when alone. We show that the costs of congestion can be higher than for a comparable population of individuals living alone. The costs can be even higher if spouses collaborate with each other when choosing their departure times. To calibrate the model we estimate trip-timing preferences for married and unmarried men and women in the Greater Paris region.

Jel Classifications: D11, D70, R41.
\end{abstract}

KEYWORDS: departure-time decisions; congestion; schedule delay costs; couple decision making; Pareto efficiency; collective models.

\section{Introduction}

Since the seminal work of Vickrey (1969) there has been growing interest in trip-timing decisions and the dynamics of traffic congestion. This has led to burgeoning literatures in transportation economics, transportation engineering, and regional science on the development of dynamic and operational models of commuting and non-commuting behavior (de Palma and Fosgerau, 2011).

In most of this literature it is assumed that agents make trip-timing decisions independently and receive payoffs at the origin and destination that do not depend on whether other agents are present. Yet many activities at work, at home,

\footnotetext{
${ }^{*}$ Ecole Normale Supérieure de Cachan and Ecole Polytechnique. Email: andre.depalma@ens-cachan.fr.

${ }^{\dagger}$ Corresponding author: Sauder School of Business, University of British Columbia, 2053 Main Mall, Vancouver, British Columbia, Canada V6T 1Z2. E-mail: robin.lindsey@sauder.ubc.ca Voice: 1-604-822-3323; Fax: 1-604-822-9574

‡ThEMA, Université de Cergy-Pontoise, 33 Bd. du Port, 95011, Cergy Cedex, and Ecole Polytechnique, FRANCE. Email: nathalie.picard@u-cergy.fr.
} 
and elsewhere can only be undertaken collaboratively (e.g. business meetings, team sports). Other activities such as leisure interests are more productive or enjoyable when other people are present. Models are being developed that attempt to deal with the need for people to be present simultaneously to engage in synergistic activities. Some models also consider the negative externalities that interactive activities induce such as congestion and pollution. Such models are challenging because of the time dimension involved, and the combinatorial explosion in the number of possible decisions by interacting agents. Positive and negative externalities are sometimes taken into account in numerical models (but with somewhat ad-hoc behavior), or in operations research models (for example, when two people have to meet as in Fosgerau et al. (2014)). Research on activity analysis is making inroads (see, for example Bhat and Pendyala, 2005, Timmermans and Zhang, 2009, and Pinjari and Bhat, 2011), but much remains to be done.

In this paper we focus on interactions and synergies that occur within the family, and examine their implications for trip-timing decisions and traffic congestion. We consider a specific setting: two-person households and the morning commute. Individuals value the presence of their spouse, and enjoy a "marital premium" in utility when they are home together. One person leaves for work while their spouse is home. The second spouse leaves for work later, works at home, or does not work. In choosing when to depart, the first spouse imposes both an externality on his/her spouse and a traffic congestion externality on commuters outside the household. Our analysis focuses on two composite questions. First, how does the marital premium affect trip-timing decisions and social welfare? Second, how does cooperative or altruistic behaviour between couples affect the utility of each person and social welfare? It is intuitively clear that cooperative behaviour within couples should increase the well-being of at least one member of the couple. However, given unpriced traffic congestion it is not obvious whether this limited form of cooperation is socially beneficial.

To describe household trip-timing preferences and the dynamics of traffic congestion we use a version of Vickrey's (1969) bottleneck model due to Vickrey (1973) in which agents maximize utility rather than minimize travel costs. Our variant of the model incorporates two elements that are important for family relationships. One is that, as Becker (1991) notes, spouses are generally altruistic to each other. We assume each spouse values the utility of the other spouse without actually deriving utility from the spouse's utility directly. This is consistent with what is sometimes referred to as paternalistic (Pollak, 1988) or nondeferential (Pollak, 2003) preferences. $^{1}$

The second element is that, since spouses live together and know each other very well, their decisions are likely to be Pareto-optimal in the sense that the well-being of one spouse cannot be improved without making the other spouse worse off. In his "collective model", Chiappori (1988) showed that when spouses make Pareto-optimal decisions, they jointly behave as if they maximize

\footnotetext{
${ }^{1}$ The case in which individuals do obtain direct utility from other people's utility is usually referred to as caring preferences.
} 
a weighted sum of their (selfish) utilities where the weights are referred to as Pareto weights. ${ }^{2}$ Pareto-optimality is consistent with the idea that spouses are able to implement any agreement that is mutually beneficial.

Collective models are increasingly used in the economics literature to study household labor supply and consumption decisions, and they hold promise for transportation applications too. For example, Chiappori et al. (2011) disentangle the roles of Pareto weights and spouses' values of time in a residential location model. In their model, spouses' workplaces are predetermined, and residential location determines spouses's commuting times. See de Palma et al. (2014) for a recent survey on family models in transportation and time use literature, and Picard et al. (2014) for another survey on family models oriented towards residential location, land use, and transport interaction.

Two recent studies that use a variant of the Vickrey (1973) bottleneck model examine scenarios involving endogenous trip-timing preferences that resemble ours in some respects. One is Fosgerau and Small (2014) who study the dynamics of morning commute traffic congestion when agglomeration economies exist both at work and in nonwork activities. Fosgerau and Small adopt an aggregate specification of these economies by assuming that worker productivity increases with the total number of people in the population simultaneously at work, and also that utility elsewhere (e.g., at home) is an increasing function of the total number of people simultaneously present at the non-work location. By contrast, in our model synergies exist only within couples that each comprise a negligible fraction (i.e., measure zero) of the total traveling population.

The other study by Gubins and Verhoef (2011/2014) examines the effects of using teleworking technology at home on morning commute departure-time decisions. Gubins and Verhoef assume that the technology increases utility of being at home in much the same way as marriage increases utility in our model. They assume that workers decide individually whether to adopt the technology. Thus, in contrast to Fosgerau and Small (2014), where trip-timing preferences depend on collective decisions, in Gubins and Verhoef preferences are determined by individual technology adoption decisions. Gubins and Verhoef derive both the equilibrium and socially optimal penetration rates. They show that adoption causes departures to begin later. The reason is similar to that in our model, but the welfare analyses in the two papers differ.

The paper is organized as follows. The next section summarizes the Vickrey (1973) model for single (independent) individuals, and derives the equilibrium which serves as a benchmark for the equilibria with couples. Section 3 derives the equilibrium for a population of couples with a man and a woman whose utilities are interdependent in the sense that each person values his or her spouse's company at home. The departure time of the spouse who leaves home first (assumed to be the man) affects both his own utility and the utility of his spouse. Following the collective model approach, the household jointly maximizes a weighted sum of the spouses' utilities. The weight on the man's utility is normalized to 1 , whereas the weight on the wife's utility is quantified

\footnotetext{
${ }^{2}$ Chiappori (1992) later extended this result to the case of caring preferences.
} 
by a nonnegative "Pareto weight". Section 4 considers the polar case of selfish or "noncooperative" behavior in which the Pareto weight is 0 , in which case the man maximizes his own utility. Section 5 provides a parallel analysis for "cooperative" behavior in which the wife's Pareto weight is positive. Section 6 uses data from a survey in the Greater Paris region to estimate trip-timing preferences including the marital premiums of men and women. We use the estimates to assess how marriage and cooperation between couples affect the costs of traffic congestion. Section 7 concludes with a summary of the main results and ideas for further research.

\section{Individuals living alone}

In the benchmark regime individuals live alone and do not interact directly although their equilibrium utilities are interdependent because of traffic congestion. A continuum of $N$ identical individuals commute alone by car from a common origin to a common destination connected by one road with capacity $s$ that is subject to bottleneck queuing delay. ${ }^{3}$ Free-flow travel time on the road is normalized to zero. We model a portion of the day, starting at time zero when everybody is at home and finishing at time $T$ after everyone who commutes is at work.

Let $t_{0}$ be the time when departures from the origin begin, and $r$ the aggregate departure rate. A person departing at time $t^{d}$ experiences queuing delay of:

$$
q\left(t^{d}\right)=\frac{1}{s}\left[\int_{u=t_{0}}^{t^{d}} r(u) d u-s\left(t_{d}-t_{0}\right)\right] .
$$

Differentiating this expression with respect to $t^{d}$ yields

$$
\frac{d q\left(t^{d}\right)}{d t^{d}}=\frac{r\left(t^{d}\right)-s}{s} .
$$

Arrival time, $t^{a}$, is related to departure time by the equation $t^{a}=t^{d}+q\left(t^{d}\right)$. Hence

$$
\frac{d t^{a}}{d t^{d}}=\frac{d\left(t^{d}+q\left(t^{d}\right)\right)}{d t^{d}}=\frac{r\left(t^{d}\right)}{s} .
$$

Individuals derive a flow of utility that is activity-specific. Three activities are considered: time spent at home, time spent driving to work, and time spent at work. Individuals have a common desired arrival time at work, $t^{*}$. To simplify the analysis and facilitate comparisons with the bottleneck model literature, utility is assumed to be proportional to the duration of each activity so that preferences can be expressed per unit of time. Unit utilities are denoted as follows: $v^{I}$ for time at home, $v$ for time in the car, $v^{E}$ for time at work before $t^{*}, v^{W}$ for time at work during regular hours, and $v^{P}$ for time missed at work due to late arrival. Arriving late at work therefore causes a utility loss per minute of $v^{L}=v^{W}-v^{P}$. The unit utilities are ranked as follows:

\footnotetext{
${ }^{3} \mathrm{~A}$ notational glossary is found at the end of the paper.
} 


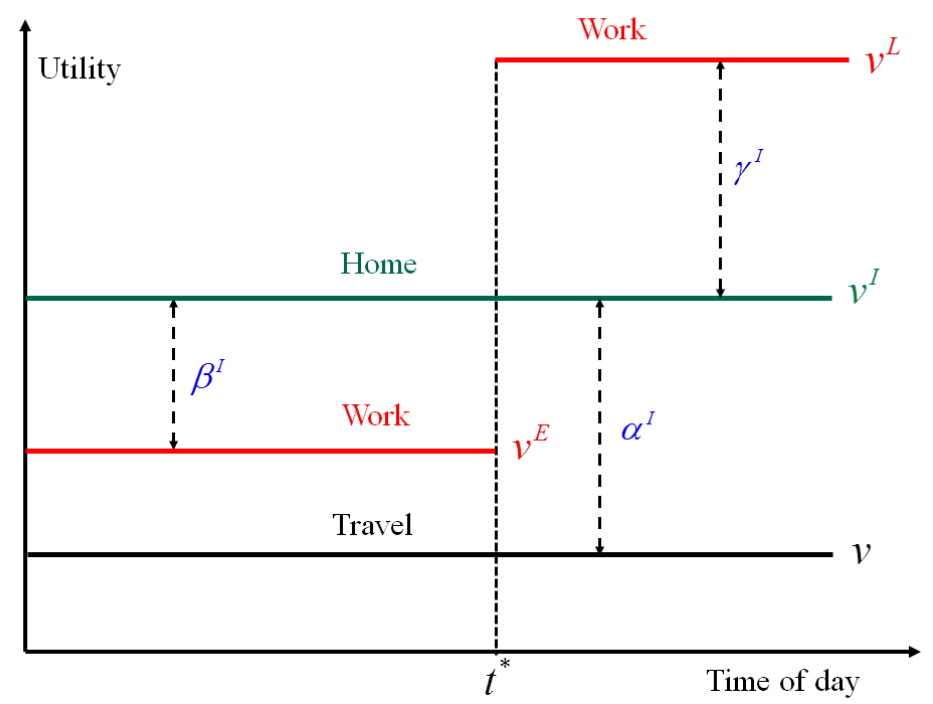

Figure 1: Trip-timing preferences and implied costs before marriage. Based on Gubins and Verhoef (2011/2014) and Tseng and Verhoef (2008).

\section{Assumption 1 (Parameter rankings for individuals)}

$$
v^{L}>v^{I}>v^{E}>v
$$

These rankings have intuitive interpretations:

$v^{E}>v$ : time spent at work early is valued more highly than time spent driving. ${ }^{4}$

$v^{I}>v$ : time spent at home is valued more highly than time spent driving. In the traditional cost-minimizing approach in the bottleneck model, the unit cost or value of travel time (VOT) is denoted $\alpha^{I} \equiv v^{I}-v$.

$v^{I}>v^{E}$ : time spent at home is valued more highly than time spent at work before $t^{*}$. People therefore prefer not to work more than their regular work hours at the expense of time at home. In the cost-minimizing approach, the unit cost of arriving early is $\beta^{I} \equiv v^{I}-v^{E}$.

$v^{L}>v^{I}$ : time spent at work after $t^{*}$ is valued more highly than time spent at home. People therefore prefer not to arrive at work late. In the cost-minimizing approach, the unit cost of arriving late is $\gamma^{I} \equiv v^{L}-v^{I}$.

The correspondence between the utility parameters and the cost parameters is shown in Figure 1. ${ }^{5}$

\footnotetext{
${ }^{4}$ The assumption $v^{E}>v$ implies that individuals do not dawdle on the way to work, and would take the shortest route if they had a choice of route.

${ }^{5}$ Figure 1 replicates, except for notation, Figure 1 in Gubins and Verhoef $(2011 / 2014)$ which, in turn, is based on Tseng and Verhoef (2008).
} 


\subsection{Equilibrium departure rates}

In equilibrium, individuals depart from home over a connected time interval $\left[t_{0}, t_{e}\right]$. The first person arrives at work early, and the last person arrives late. The departure time for which someone arrives on time (at $t^{*}$ ) is denoted $\tilde{t}$ where $\tilde{t} \in\left(t_{0}, t_{e}\right)$. Individuals who depart during the interval $\left[t_{0}, \tilde{t}\right)$ arrive early (denoted by subscript "E") and receive a utility $U_{E}\left(t^{d}\right)=v^{I} t^{d}+v\left(t^{a}-t^{d}\right)+$ $v^{E}\left(t^{*}-t^{a}\right)+v^{W}\left(T-t^{*}\right)$, or

$$
U_{E}\left(t^{d}\right)=\left(v^{I}-v\right) t^{d}+\left(v-v^{E}\right) t^{a}+v^{E} t^{*}+v^{W}\left(T-t^{*}\right) .
$$

Individuals who depart during the interval $\left(\tilde{t}, t_{e}\right]$ arrive late, denoted by subscript "L", and receive a utility $U_{L}\left(t^{d}\right)=v^{I} t^{d}+v\left(t^{a}-t^{d}\right)+v^{P}\left(t^{a}-t^{*}\right)+$ $v^{W}\left(T-t^{a}\right)$, or (using $\left.v^{L}=v^{W}-v^{P}\right)$

$$
U_{L}\left(t^{d}\right)=\left(v^{I}-v\right) t^{d}+\left(v-v^{L}\right) t^{a}+v^{L} t^{*}+v^{W}\left(T-t^{*}\right) .
$$

The last two terms in (3) and (4) do not depend on departure or arrival times. The first term is the same, and the second term differs only in that parameter $v^{E}$ appears for early arrival and parameter $v^{L}$ for late arrival. During a time interval in which departures occur, utility must be constant. Differentiating (3) and (4) with respect to $t^{d}$, and using eq. (1), this implies:

$$
\begin{aligned}
& r_{E}^{I}=\frac{v^{I}-v}{v^{E}-v} s>s, \\
& r_{L}^{I}=\frac{v^{I}-v}{v^{L}-v} s<s,
\end{aligned}
$$

where superscript $I$ denotes the equilibrium with independent or single individuals. Given $v^{L}>v^{I}>v^{E}$ as per Assumption 1, the equilibrium departure rate exceeds bottleneck capacity during early arrivals and is below capacity during late arrivals. Queuing delay therefore evolves over time to offset the advantage of arriving at work closer to the preferred time, and hence to maintain the equal-utility condition while individuals are departing.

The on-time departure time, $\widetilde{t}$, is defined by the condition

$$
\tilde{t}+\frac{r_{E}^{I}-s}{s}\left(\tilde{t}-t_{0}\right)=t^{*},
$$

which gives:

$$
\widetilde{t}^{I}=\frac{v^{E}-v}{v^{I}-v} t^{*}+\frac{v^{I}-v^{E}}{v^{I}-v} t_{0} .
$$

\subsection{Equilibrium trip timing and utility}

In equilibrium, all individuals derive the same utility although the composition of utility differs from person to person. Equilibrium utility is derived using two conditions. 
The first condition is that the first and last individuals to depart have the same utility: $U_{E}\left(t_{0}\right)=U_{L}\left(t_{e}\right)$. From eqs. (3) and (4) this gives:

$$
\left(v^{I}-v\right) t_{0}+\left(v-v^{E}\right) t_{0}+v^{E} t^{*}=\left(v^{I}-v\right) t_{e}+\left(v-v^{L}\right) t_{e}+v^{L} t^{*} .
$$

The second condition is that the departure period is just long enough for everyone to pass the bottleneck. Since the road is used at full capacity throughout the departure period,

$$
s\left(t_{e}-t_{0}\right)=N .
$$

Equations (8) and (9) can be solved for the equilibrium values of $t_{0}$ and $t_{e}$ :

$$
\begin{aligned}
& t_{0}^{I}=t^{*}-\frac{v^{L}-v^{I}}{v^{L}-v^{E}} \phi, \\
& t_{e}^{I}=t^{*}+\frac{v^{I}-v^{E}}{v^{L}-v^{E}} \phi,
\end{aligned}
$$

where $\phi \equiv N / s$. The on-time departure time is solved by substituting (10) into (7):

$$
\widetilde{t}^{I}=t^{*}-\frac{\left(v^{I}-v^{E}\right)\left(v^{L}-v^{I}\right)}{\left(v^{I}-v\right)\left(v^{L}-v^{E}\right)} \phi .
$$

The number of people who arrive early is

$$
N_{E}^{I}=r_{E}^{I}\left(\widetilde{t}^{I}-t_{0}^{I}\right)=s\left(t^{*}-t_{0}^{I}\right)=\frac{v^{L}-v^{I}}{v^{L}-v^{E}} N,
$$

and the number who arrive late is

$$
N_{L}^{I}=r_{L}^{I}\left(t_{e}^{I}-\widetilde{t}^{I}\right)=s\left(t_{e}^{I}-t^{*}\right)=\frac{v^{I}-v^{E}}{v^{L}-v^{E}} N .
$$

Substituting (10) into (3) (or (11) into (4)) yields

$$
U^{I}=v^{I} t^{*}+v^{W}\left(T-t^{*}\right)-\Psi^{I} \phi
$$

where $\Psi^{I} \equiv \frac{\left(v^{I}-v^{E}\right)\left(v^{L}-v^{I}\right)}{v^{L}-v^{E}}=\frac{\beta^{I} \gamma^{I}}{\beta^{I}+\gamma^{I}}$. If there were no congestion, equilibrium utility would be given by the first two terms in (15). The last term corresponds to the disutility or cost of congestion:

$$
C^{I}=\Psi^{I} \phi
$$

\section{Couples living together}

We now extend the model to accommodate men and women. There are $N$ men identified by subscript $m$, and $N$ women identified by subscript $w$. The men all work and commute on the same route which has a bottleneck with a flow capacity of $s_{m}$. Men have a common work start time of $t_{m}^{*}$, and preferences 
consistent with Assumption 1. All the formulae derived in Section 2 for $N$ single individuals therefore apply to men. Before marriage, men incur a congestion cost of:

$$
C_{m}^{I}=\Psi_{m}^{I} \phi_{m}
$$

where $\phi_{m} \equiv N / s_{m}$, and $\Psi_{m}^{I} \equiv \frac{\left(v_{m}^{I}-v_{m}^{E}\right)\left(v_{m}^{L}-v_{m}^{I}\right)}{v_{m}^{L}-v_{m}^{E}}$.

Having lived apart, men and women now marry to form $N$ couples. ${ }^{6}$ Each woman in a couple does one of three things: She may work out of home, she may work at home, or she may not work. Two additional assumptions are required if she works out of home. First, she commutes on a different route than men so that men and women do not impede each other on the road. ${ }^{7}$ Second, she leaves home after her husband. This implies that her utility is affected by his departure-time decision, but her departure-time choice (if she works) does not affect him. For the purpose of comparing travel before and after marriage, it is thus unnecessary to describe women's travel. ${ }^{8}$

Marriage is assumed to be agreeable in the sense that spouses value time spent at home more when together than when alone. ${ }^{9}$ This assumption is formalized by supposing that utility per unit time while at home with a spouse is $v_{m}^{M} \geq v_{m}^{I}$ for men, and $v_{w}^{M} \geq v_{w}^{I}$ for women, where superscript $M$ denotes married. The additional marginal utility derived from a spouse's presence will be called the "marital premium" and written $\Delta_{m} \equiv v_{m}^{M}-v_{m}^{I}$ for men, and $\Delta_{w} \equiv v_{w}^{M}-v_{w}^{I}$ for women. ${ }^{10}$

Intuition strongly suggests that benefit parameters $v_{i}, v_{i}^{E}$ and $v_{i}^{L}, i=m, w$, are the same before and after marriage, since neither driving nor being at work early or late involve the spouse. The unit cost parameters for married men become $\alpha_{m}^{M} \equiv v_{m}^{M}-v_{m}, \beta_{m}^{M} \equiv v_{m}^{M}-v_{m}^{E}$, and $\gamma_{m}^{M} \equiv v_{m}^{L}-v_{m}^{M}$. For men, the VOT rises by $\alpha_{m}^{M}-\alpha_{m}^{I}=v_{m}^{M}-v_{m}^{I}=\Delta_{m}$ (the marital premium), the cost of arriving early at work rises by $\Delta_{m}$, and the cost of arriving at work late falls by $\Delta_{m}$. These changes are shown in Figure 2 .

To allow for cooperative behavior within couples we consider a collective model "a la Chiappori" in which spouses coordinate to choose their departure time(s) in order to jointly maximize a sum of their utilities, weighted by Pareto weights. The man's Pareto weight is normalized to 1, and the woman's weight

\footnotetext{
${ }^{6}$ Same-sex couples can be accommodated in the model with minor changes in notation.

${ }^{7}$ This assumption greatly simplifies the analysis. Equilibria are much more complicated to derive if men and women use the same route.

${ }^{8}$ The analysis is unchanged if the roles of men and women are reversed. We assume that men leave home for work before women because this is true of a majority of couples in our dataset. In a preliminary version of this paper we treated women in the same way as men by assuming that all women work, have a common work-start time, $t_{w}^{*}$, and traverse a common bottleneck with capacity $s_{w}$. We further assumed that $t_{w}^{*}>t_{m}^{*}$ and that all women leave home after their husbands. Adopting this specification introduced additional notation and algebra without affecting any results of interest.

${ }^{9}$ There is little reported empirical evidence to evaluate this assumption. In support of it, Bradley and Vovsha (2005) find that individuals generally derive additional utility from joint participation, both in mandatory activities (e.g., traveling to work) and non-mandatory activities (e.g., staying at home). In Section 6 we present some new evidence.

${ }^{10}$ The marital premium can include utility from the presence of children at home.
} 


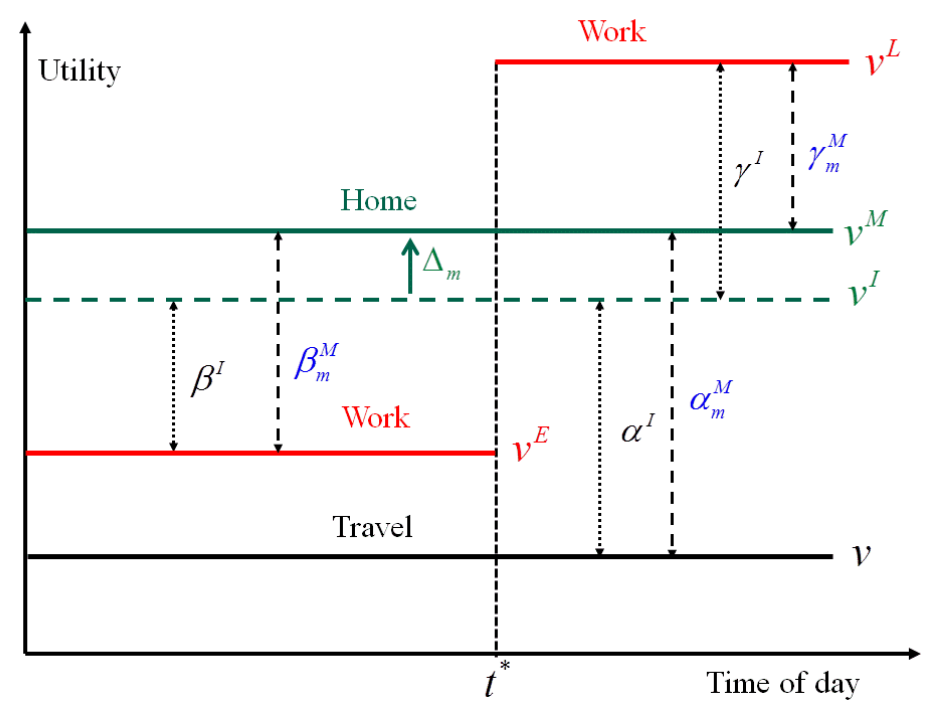

Figure 2: Trip-timing preferences and implied costs for men after marriage

is denoted by $\lambda \geq 0$. Noncooperative behavior corresponds to the limiting case $\lambda=0$.

Since a man's utility does not depend on his wife's departure time, the woman's departure time (if she works) does not depend on the woman's Pareto weight (or, equivalently, bargaining power). However, the wife's utility does depend on her husband's departure time so that the man's departure time selected by the couple depends on $\lambda$. Since the wife is home when her husband leaves for work, her husband confers a benefit on her of $\Delta_{w}$ for each minute he delays leaving home. Following Chiappori (1988), the man behaves "as if" he attaches a weight $\lambda \Delta_{w}$ to this benefit. It is assumed that the man does not derive personal utility from his wife's utility. ${ }^{11}$ This assumption is critical for assessing the welfare effects of cooperation.

Nevertheless, the man behaves as if his marginal value of time spent at home rises to $v_{m}^{M}+\lambda \Delta_{w}$ which causes further shifts of $\alpha_{m}^{M}, \beta_{m}^{M}$, and $\gamma_{m}^{M}$. (To avoid clutter, these shifts are not shown in Figure 2.) To assure that the equilibrium early departure rate of men is finite for all values of $\lambda$, the unit benefit rankings in Assumption 1 must be revised, and the rankings become:

\section{Assumption 2 (Parameter rankings for men)}

$$
v_{m}^{L}>v_{m}^{M}+\lambda \Delta_{w} \geq v_{m}^{I}>v_{m}^{E}>v_{m} .
$$

\footnotetext{
${ }^{11}$ The man is therefore assumed to have paternalistic or nondeferential preferences rather than caring preferences.
} 


\subsection{Equilibrium departures}

The equilibrium trip timing and departure rates for married men are derived in the same way as in Section 2. The formulas can be obtained from the formulas for single individuals simply by adding subscript $m$, and replacing $v_{m}^{I}$ with $v_{m}^{M}+\lambda \Delta_{w}$. The solution is:

$$
\begin{aligned}
r_{m E}^{M} & =\frac{v_{m}^{M}+\lambda \Delta_{w}-v_{m}}{v_{m}^{E}-v_{m}} s_{m}>s_{m}, \\
r_{m L}^{M} & =\frac{v_{m}^{M}+\lambda \Delta_{w}-v_{m}}{v_{m}^{L}-v_{m}} s_{m}<s_{m}, \\
t_{0 m}^{M} & =t^{*}-\frac{v_{m}^{L}-v_{m}^{M}-\lambda \Delta_{w}}{v_{m}^{L}-v_{m}^{E}} \phi_{m}, \\
t_{e m}^{M} & =t^{*}+\frac{v_{m}^{M}+\lambda \Delta_{w}-v_{m}^{E}}{v_{m}^{L}-v_{m}^{E}} \phi_{m} .
\end{aligned}
$$

The corresponding equations for single men are (5), (6), (10) and (11). Given $v_{m}^{M}+\lambda \Delta_{w}>v_{m}^{I}$, married men begin to leave later in the morning than single men, but they then depart at a faster rate. This is because married men value time at home more than unmarried men, and are therefore willing to incur more congestion delay on their commute as a price for staying longer at home. ${ }^{12}$ As explained below, this change in trip timing affects utility for both men and women.

For future reference we write the utilities for men who depart early or late:

$$
\begin{aligned}
& U_{m E}\left(t_{m}^{d}\right)=\left(v_{m}^{M}-v_{m}\right) t_{m}^{d}+\left(v_{m}-v_{m}^{E}\right) t_{m}^{a}+v_{m}^{E} t_{m}^{*}+v_{m}^{W}\left(T_{m}-t_{m}^{*}\right), \\
& U_{m L}\left(t_{m}^{d}\right)=\left(v_{m}^{M}-v_{m}\right) t_{m}^{d}+\left(v_{m}-v_{m}^{L}\right) t_{m}^{a}+v_{m}^{L} t_{m}^{*}+v_{m}^{W}\left(T_{m}-t_{m}^{*}\right) .
\end{aligned}
$$

These formulas are counterparts to (3) and (4) for single individuals.

\subsection{Equilibrium utilities}

In this section we solve for average equilibrium utilities of men and women. Since men depart for work at different times, their wives attain different utilities in equilibrium. Similarly, except if $\lambda=0$ men attain different utilities as well even though they leave home before their wives. It is straightforward but tedious to derive average utilities for each sex (see the appendix). Average equilibrium utility for men is given by the counterpart to eq. (15):

$$
\begin{aligned}
\bar{U}_{m}^{M}= & v_{m}^{M} t_{m}^{*}+v_{m}^{W}\left(T_{m}-t_{m}^{*}\right)- \\
& \frac{\left\{\begin{array}{l}
\left(v_{m}^{L}-v_{m}^{M}-\lambda \Delta_{w}\right)\left(2\left(v_{m}^{M}-v_{m}\right)+\lambda \Delta_{w}\right)\left(v_{m}^{M}-v_{m}^{E}\right)+ \\
\left(v_{m}^{L}-v_{m}^{E}\right)\left(v_{m}^{M}-v_{m}\right) \lambda \Delta_{w}-\left(v_{m}^{E}-v_{m}^{M}-\lambda \Delta_{w}\right) \lambda^{2} \Delta_{w}^{2}
\end{array}\right\}}{2\left(v_{m}^{L}-v_{m}^{E}\right)\left(v_{m}^{M}+\lambda \Delta_{w}-v_{m}\right)} \phi_{m},
\end{aligned}
$$

\footnotetext{
${ }^{12}$ Similar shifts occur in the Gubins and Verhoef (2011/2014) model when workers adopt telecommuting technology and become more productive at home.
} 
where the bar in $\bar{U}_{m}^{M}$ indicates an average value. For women, the relevant component of utility is the change in utility due to marriage which equals $\Delta_{w}$ multiplied by the average value of $t_{m}^{d}$ for men. This works out to:

$$
\bar{U}_{w}^{M}-U_{w}^{I}=\Delta_{w} N^{-1} \int_{n=0}^{N} t_{m}^{d}(n) d n=\Delta_{w} t_{m}^{*}+\Delta \bar{U}_{w}^{I M},
$$

where

$$
\Delta \bar{U}_{w}^{I M} \equiv \frac{\Delta_{w}}{2\left(v_{m}^{L}-v_{m}^{E}\right)} \cdot\left[\begin{array}{c}
2\left(v_{m}^{M}+\lambda \Delta_{w}\right)-v_{m}^{E}-v_{m}^{L}- \\
\frac{\left(v_{m}^{M}+\lambda \Delta_{w}-v_{m}^{E}\right)\left(v_{m}^{L}-v_{m}^{M}-\lambda \Delta_{w}\right)}{v_{m}^{M}+\lambda \Delta_{w}-v_{m}}
\end{array}\right] \phi_{m} .
$$

Term $\Delta_{w} t_{m}^{*}$ in eq. (26) is the increase in utility for women from marriage if there were no congestion on the men's commuting route. This term will be disregarded in assessing the welfare effects of marriage on travel costs. The remaining term, $\Delta \bar{U}_{w}^{I M}$, is the utility (or disutility) caused by adjustments in men's departure times due to traffic congestion. This term is proportional to the duration of congestion on the men's route, $\phi_{m} \cdot{ }^{13}$

Eqs. (25) and (26) are rather complex, and do not yield easy-to-digest results. We proceed in two steps. First, we assume that $\lambda=0$ so that men disregard their wives' utilities when choosing when to leave home. We refer to this case as "noncooperative couples". Second, we assume that $\lambda>0$ so that men behave "as if" they attach a positive weight to their wives' utilities. We refer to this case as "cooperative couples". At each step we focus on how changes in men's preferences affect travel-related utility for the two sexes.

\section{Noncooperative Equilibrium}

\subsection{Utility of men}

With $\lambda=0$, all men receive the same utility in equilibrium because they disregard their wives' utilities. Eq. (25) simplifies to

$$
U_{m}^{N}=v_{m}^{M} t_{m}^{*}+v_{m}^{W}\left(T_{m}-t_{m}^{*}\right)-\Psi_{m}^{N} \phi_{m}
$$

where $N$ denotes the noncooperative equilibrium and $\Psi_{m}^{N} \equiv \frac{\left(v_{m}^{M}-v_{m}^{E}\right)\left(v_{m}^{L}-v_{m}^{M}\right)}{v_{m}^{L}-v_{m}^{E}}$. The last term in (27) is the cost of congestion on the men's route:

$$
C_{m}^{N}=\Psi_{m}^{N} \phi_{m}
$$

Men experience a change in utility from marriage of:

$$
\begin{gathered}
U_{m}^{N}-U_{m}^{I}= \\
\Delta_{m} t_{m}^{*}+\frac{1}{v_{m}^{L}-\nu_{m}^{E}}\left[\left(v_{m}^{I}-v_{m}^{E}\right)\left(v_{m}^{L}-v_{m}^{I}\right)-\left(v_{m}^{M}-v_{m}^{E}\right)\left(v_{m}^{L}-v_{m}^{M}\right)\right] \phi_{m}=
\end{gathered}
$$

\footnotetext{
${ }^{13}$ To understand this, note that if $\phi_{m}=0$ all men would leave home at $t_{m}^{*}$ in both the singles and the couples equilibria. Marriage would not affect men's departure times, and there would be no spillover effect on women.
} 


$$
\underbrace{\Delta_{m} t_{m}^{*}}_{>0}+\underbrace{\frac{\Delta_{m}}{v_{m}^{L}-v_{m}^{E}}\left[\left(v_{m}^{I}+v_{m}^{M}\right)-\left(v_{m}^{E}+v_{m}^{L}\right)\right] \phi_{m}}_{\Delta U_{m}^{I N}} .
$$

The first term in eq. (29) is the utility gained from marriage if men encountered no traffic congestion. Similar to the treatment for women, this term will be disregarded in assessing the welfare effects of marriage on travel costs. The second term, $\Delta U_{m}^{I N}$, corresponds to the difference in congestion costs for the singles $(I)$ and noncooperative-couples $(N)$ equilibria which is proportional to:

$$
\Gamma_{m}^{I N} \equiv\left(v_{m}^{I}+v_{m}^{M}\right)-\left(v_{m}^{E}+v_{m}^{L}\right)=\underbrace{\left(v_{m}^{I}-v_{m}^{E}\right)}_{>0}-\underbrace{\left(v_{m}^{L}-v_{m}^{M}\right)}_{>0} .
$$

The signs of the two component terms in $\Gamma_{m}^{I N}$ follow from Assumption 2. Expression (30) can be positive or negative. This result is formalized as:

Proposition 1 (Marriage and congestion: men) If spouses do not cooperate when choosing their departure times, marriage may increase or decrease utility due to congestion for men. Utility increases if $\left(v_{m}^{I}+v_{m}^{M}\right)>\left(v_{m}^{E}+v_{m}^{L}\right)$.

Loosely speaking, Proposition 1 says that men's utility increases if they value time spent at home more than time spent at work. To see why, note that disutility from congestion is governed by the strength of trip-timing preferences. Before $t^{*}$, unmarried men prefer time at home to time at work by a margin $\beta_{m}^{I} \equiv v_{m}^{I}-v_{m}^{E}$ per minute. After $t^{*}$, they prefer to be at work by a margin $\gamma_{m}^{I} \equiv v_{m}^{L}-v_{m}^{I}$. For given values of $v_{m}^{E}$ and $v_{m}^{L}$, congestion is most costly when the two margins are equal because men then cannot exploit the lower cost by arriving primarily early or primarily late. As noted above, since $v_{m}^{M}>v_{m}^{I}$, marriage increases the penalty for arriving early and reduces the penalty for arriving late as shown in Figure 2. Disutility from congestion is therefore lower after marriage if $\beta_{m}^{I}$ is initially larger than $\gamma_{m}^{I}$, a condition that translates into the inequality in Proposition 1.

For future reference we rewrite the condition in Proposition 1 in terms of unit costs:

$$
\Delta U_{m}^{I N}>0 \Longleftrightarrow \Gamma_{m}^{I N} \stackrel{s}{=} \frac{\beta_{m}^{I}}{\alpha_{m}^{I}}-\frac{\gamma_{m}^{I}}{\alpha_{m}^{I}}+\frac{\Delta_{m}}{\alpha_{m}^{I}}>0,
$$

where $\stackrel{s}{=}$ means identical in sign. According to most empirical studies (e.g., Small (1982) and de Palma and Rochat (1997)), the unit cost of arriving late at work $(\gamma)$ is several times as large as the unit cost of arriving early $(\beta)$. No published empirical studies have estimated the size of the marital premiums, $\Delta_{m}$ and $\Delta_{w}$. Section 6 will present estimates suggesting that $\Delta_{m}$ and $\Delta_{w}$ are fairly small compared to the $\alpha, \beta$ and $\gamma$ values. If so, condition (31) is likely to be violated so that marriage increases disutility from congestion for men.

For the balance of this section and Section 5 it is useful to keep some benchmark values in mind. We take these to be $\beta_{m} / \alpha_{m}=1 / 2$ and $\gamma_{m} / \alpha_{m}=2$. We will also suppose that $\Delta_{m} / \alpha_{m}$ and $\Delta_{w} / \alpha_{m}$ are fairly small so that the values of $\beta_{m} / \alpha_{m}$ and $\gamma_{m} / \alpha_{m}$ are similar for single and married individuals. These parameter ratios will suffice to sign the changes in utility that will be considered. 


\subsection{Utility of women}

In the noncooperative equilibrium, women are not affected by traffic congestion on the men's route before marriage, but they are affected after marriage because their utility depends on when their husbands leave for work. With $\lambda=0$, eq. (26) for women's average utility simplifies somewhat to

$\Delta \bar{U}_{w}^{I N}=\frac{\Delta_{w}}{2\left(v_{m}^{L}-v_{m}^{E}\right)}[\underbrace{\left(v_{m}^{M}-v_{m}^{E}\right)}_{(a): \beta_{m}^{M}>0}-\underbrace{\left(v_{m}^{L}-v_{m}^{M}\right)}_{(b): \gamma_{m}^{M}>0}-\underbrace{\frac{\left(v_{m}^{M}-v_{m}^{E}\right)\left(v_{m}^{L}-v_{m}^{M}\right)}{v_{m}^{M}-v_{m}}}_{(c): \beta_{m}^{M} \gamma_{m}^{M} / \alpha_{m}^{M}>0}] \phi_{m}$.

The effect on women of traffic congestion on the men's route is determined by the sign of the expression in square brackets in eq. (32). This leads to:

Proposition 2 (Marriage and congestion: women) If spouses do not cooperate when choosing their departure times, women benefit from congestion on the men's route if $v_{m}^{M}-v_{m}^{E}-\left(v_{m}^{L}-v_{m}^{M}\right)-\frac{\left(v_{m}^{M}-v_{m}^{E}\right)\left(v_{m}^{L}-v_{m}^{M}\right)}{v_{m}^{M}-v_{m}}>0$.

Converting this condition to unit costs, dividing through by $\alpha_{m}^{M}$, and using the benchmark parameter values, one obtains $\beta_{m} / \alpha_{m}-\gamma_{m} / \alpha_{m}-\left(\beta_{m} / \alpha_{m}\right)$. $\left(\gamma_{m} / \alpha_{m}\right)=1 / 2-2-1 / 2 \cdot 2=-5 / 2$. This suggests that women are likely to be worse off from congestion. The condition in Proposition 2 can also be written

$$
\Delta \bar{U}_{w}^{I N}>0 \Longleftrightarrow \Gamma_{w}^{I N} \equiv \frac{\left(\alpha_{m}^{I}+\Delta_{m}\right)\left(\beta_{m}^{I}+\Delta_{m}\right)}{\alpha_{m}^{I}+\beta_{m}^{I}+2 \Delta_{m}}-\gamma_{m}^{I}+\Delta_{m}>0 .
$$

Similar to $\Gamma_{m}^{I N}$ for men, $\Gamma_{w}^{I N}$ is an increasing function of the cost of early arrival $\left(\beta_{m}^{I}\right)$, a decreasing function of the cost of late arrival $\left(\gamma_{m}^{I}\right)$, and an increasing function of $\Delta_{m}$. Using (31) and (33) it is straightforward to show that

$$
\Gamma_{w}^{I N}-\Gamma_{m}^{I N} \stackrel{s}{=}-\left(\frac{\beta_{m}^{I}}{\alpha_{m}^{I}}\right)^{2}+\left(1-\frac{\beta_{m}^{I}}{\alpha_{m}^{I}}\right) \frac{\Delta_{m}}{\alpha_{m}^{I}}+\left(\frac{\Delta_{m}}{\alpha_{m}^{I}}\right)^{2}
$$

Expression (34) is negative for small values of $\Delta_{m}$. Thus, if the marital premium for men is small, women are more likely than men to suffer from traffic congestion on the men's route.

Assumption 2 requires $\Delta_{m}<\gamma_{m}^{I}$. If $\Delta_{m}$ is close to $\gamma_{m}^{I},(34)$ is positive when $\gamma_{m}^{I} \geq \beta_{m}^{I}$ in which case women lose less than men. It is therefore possible for either sex to benefit while the other sex loses. Nevertheless, it is clear from (33) that $\Gamma_{w}^{I N}<\beta_{m}^{I}-\gamma_{m}^{I}+2 \Delta_{m}$. Thus, if $\gamma_{m}^{I}>\beta_{m}^{I}+2 \Delta_{m}-$ consistent with the benchmark parameter values — men and women are both worse off. Men lose because the opportunity cost of arriving early at work increases proportionally more than the opportunity cost of arriving late decreases. Women lose because congestion induces men to leave home earlier on average, which increases the time women spend at home alone. 


\subsection{Utility of couples}

The effect of marriage on couple's utility can be determined from eqs. (29) and (32). The average change in couple's utility, $\Delta \bar{U}_{c}^{I N}$, works out to

$$
\begin{aligned}
& \Delta \bar{U}_{c}^{I N} \equiv \Delta U_{m}^{I N}+\Delta \bar{U}_{w}^{I N} \stackrel{s}{=}\left(v_{m}^{I}+v_{m}^{M}-\left(v_{m}^{E}+v_{m}^{L}\right)\right) \Delta_{m}+ \\
& \frac{\Delta_{w}}{2}\left(\left(v_{m}^{M}-v_{m}^{E}\right)-\left(v_{m}^{L}-v_{m}^{M}\right)-\frac{\left(v_{m}^{M}-v_{m}^{E}\right)\left(v_{m}^{L}-v_{m}^{M}\right)}{v_{m}^{M}-v_{m}}\right) .
\end{aligned}
$$

Translated to unit costs, the condition for a couple's utility to increase is:

$$
\begin{gathered}
\Delta \bar{U}_{c}^{I N}>0 \Longleftrightarrow\left(2\left(1+\frac{\Delta_{m}}{\alpha_{m}}\right) \frac{\Delta_{m}}{\alpha_{m}}+\left(1+\frac{\beta_{m}}{\alpha_{m}}+2 \frac{\Delta_{m}}{\alpha_{m}}\right) \frac{\Delta_{w}}{\alpha_{m}}\right) \frac{\gamma_{m}}{\alpha_{m}}< \\
2\left(1+\frac{\Delta_{m}}{\alpha_{m}}\right)\left(\frac{\beta_{m}}{\alpha_{m}}+\frac{\Delta_{m}}{\alpha_{m}}\right) \frac{\Delta_{w}}{\alpha_{m}}+\left(\frac{\beta_{m}}{\alpha_{m}}+2\left(1+\frac{\beta_{m}}{\alpha_{m}}\right) \frac{\Delta_{m}}{\alpha_{m}}+3\left(\frac{\Delta_{m}}{\alpha_{m}}\right)^{2}\right) \frac{\Delta_{w}}{\alpha_{m}} .
\end{gathered}
$$

Clearly, condition (36) is satisfied if conditions (31) and (33) are both satisfied, and violated if both conditions are violated. With the benchmark parameter values, and assuming $\Delta_{w}=\Delta_{m},(36)$ is violated for all admissible values of $\Delta_{m}$. It is therefore plausible that marriage causes the costs of congestion to increase for both sexes. It is of interest to compare this finding with that of Gubins and Verhoef $(2011 / 2014)$ who analyze the effects of teleworking technology on welfare. They show that, although the socially optimal penetration rate of the technology may be less than 100 percent, full penetration is always preferable to zero penetration. The reason for this is that they include in their welfare accounting the benefits that individuals derive from teleworking while at home. By contrast, we disregard the marital premium in utility received by couples while at home together.

\section{Cooperative equilibrium}

Section 4 considered the noncooperative-couples equilibrium in which spouses disregard each other's utilities. We now take the second step in assessing the effects of marriage by considering a cooperative-couples regime in which, as in Section 3, men place a weight $\lambda>0$ on their wife's utility. We derive the cooperative-couples equilibrium and compare it with the noncooperative-couples equilibrium.

The difference between the two regimes naturally depends on the size of $\lambda$. Picard et al. (2013) have derived estimates of $\lambda$ using mode choice data from the 1999 French General Census. With the Pareto weight on men's utility normalized to 1 , their estimates of $\lambda$ for women range from 1.01 to 1.22 depending on the number of vehicles in the household. This suggests that a reasonable benchmark value to use for the cooperative-couples regime is 1 , which we will call "balanced" cooperation. 
Intuition suggests that cooperation between spouses raises their joint utility. However, because congestion is an uninternalized externality in the model it is not clear a priori whether cooperation within couples benefits travelers overall. Section 4 established that marriage can increase the costs of traffic congestion for both sexes. This happens when the higher utility for married men while at home $\left(\Delta_{m}\right)$ raises the cost of departing early proportionally more than it reduces the cost of departing late. Men start to depart later (cf. eq. (21)), and then depart more rapidly (cf. eq. (19)). In a cooperative equilibrium with $\lambda>0$, these changes are reinforced because men behave as if their utility at home increases by an additional $\lambda \Delta_{w}$. The welfare impacts of the two changes are different because the man's marriage premium, $\Delta_{m}$, affects his utility directly whereas the woman's marriage premium, $\Delta_{w}$, does not because men are assumed not to care directly about their wife's utility. Nevertheless, altruism can leave one or both sexes worse off as shown below.

\subsection{Utility of men}

Consider first how cooperation affects utility of men. Utility for the first man to depart is derived by substituting eq. (21) for $t_{0 m}^{M}$ into eq. (23):

$$
U_{m E}^{C}\left(t_{0 m}\right)=v_{m}^{M} t_{m}^{*}+v_{m}^{W}\left(T_{m}-t_{m}^{*}\right)-\frac{\left(v_{m}^{M}-v_{m}^{E}\right)\left(v_{m}^{L}-v_{m}^{M}-\lambda \Delta_{w}\right)}{v_{m}^{L}-v_{m}^{E}} \phi_{m}
$$

where the superscript $C$ denotes cooperation. Given $\lambda \Delta_{w}>0$, it follows from eq. (37) that the first man to depart is better off when men cooperate. This is because cooperation induces men to postpone leaving home, and the first man arrives at work closer to $t_{m}^{*}$ without incurring any queuing delay. The utility of the last man to depart is derived by substituting eq. (22) for $t_{e m}^{M}$ into eq. (24):

$$
U_{m L}^{C}\left(t_{e m}\right)=v_{m}^{M} t_{m}^{*}+v_{m}^{W}\left(T_{m}-t_{m}^{*}\right)-\frac{\left(v_{m}^{M}-v_{m}^{E}+\lambda \Delta_{w}\right)\left(v_{m}^{L}-v_{m}^{M}\right)}{v_{m}^{L}-v_{m}^{E}} \phi_{m}
$$

The last man to depart is worse off in the cooperative equilibrium because he incurs a higher late-arrival cost. Thus, some men gain from cooperation and others lose.

Using eqs. (25) and (27) the change in average men's utility can be written

$\Delta \bar{U}_{m}^{N C} \equiv \bar{U}_{m}^{C}-U_{m}^{N}=\frac{v_{m}^{E}\left(v_{m}-v_{m}^{L}\right)+v_{m}^{M}\left(v_{m}^{M}-2 v_{m}\right)+v_{m}^{L} v_{m}-\lambda^{2} \Delta_{w}^{2}}{2\left(v_{m}^{L}-v_{m}^{E}\right)\left(v_{m}^{M}+\lambda \Delta_{w}-v_{m}\right)} \phi_{m}$.

The condition for men's average utility to increase is:

$$
\begin{gathered}
\Delta \bar{U}_{m}^{N C}>0 \Longleftrightarrow \\
v_{m}^{E}\left(v_{m}-v_{m}^{L}\right)+v_{m}^{M}\left(v_{m}^{M}-2 v_{m}\right)+v_{m}^{L} v_{m}-\lambda^{2} \Delta_{w}^{2}>0 .
\end{gathered}
$$


Condition (40) can be written in terms of parameter ratios:

$$
\begin{gathered}
\Delta \bar{U}_{m}^{N C}>0 \Longleftrightarrow \Gamma_{m}^{N C} \equiv \\
\frac{\beta_{m}}{\alpha_{m}}-\left(1-\frac{\beta_{m}}{\alpha_{m}}\right) \frac{\gamma_{m}}{\alpha_{m}}+2 \frac{\Delta_{m}}{\alpha_{m}}+\left(\frac{\Delta_{m}}{\alpha_{m}}\right)^{2}-\lambda^{2}\left(\frac{\Delta_{w}}{\alpha_{m}}\right)^{2}>0,
\end{gathered}
$$

where superscript $I$ on $\alpha_{m}, \beta_{m}$, and $\gamma_{m}$ is omitted to avoid notational clutter. Condition (41) is less stringent than condition (31) for men to benefit from marriage, but it can still be violated. Since $\beta_{m}<\alpha_{m}, \Gamma_{m}^{N C}$ is a decreasing function of $\gamma_{m}$. Thus, men suffer from cooperation if late arrival is very costly. Function $\Gamma_{m}^{N C}$ is increasing with $\Delta_{m}$ so that men are more likely to benefit if their marital premium is large. However, $\Gamma_{m}^{N C}$ is decreasing with $\Delta_{w}$ since larger values of $\Delta_{w}$ induce men to sacrifice more personal utility for their wives. Consider the benchmark values of $\beta_{m} / \alpha_{m}=0.5$ and $\gamma_{m} / \alpha_{m}=2$. If there is balanced cooperation, and men and women have equal marital premiums, $\lambda \Delta_{w}=\Delta_{m} . \Gamma_{m}^{N C}$ is negative for $\Delta_{m} / \alpha_{m}<0.25$, and positive for $\Delta_{m} / \alpha_{m}>$ 0.25 . If, instead, couples are noncooperative, so that $\lambda \Delta_{w}=0, \Gamma_{m}^{N C}$ is negative for $\Delta_{m} / \alpha_{m}<0.225$, and positive for $\Delta_{m} / \alpha_{m}>0.225$. In both cases men are better off only if their marital premium is appreciable.

\subsection{Utility of women}

The effect of cooperation on women depends on how men change their departure times. To facilitate comparisons it will be assumed that men depart in the same order in the cooperative and noncooperative regimes. Since cooperation postpones departures by increasing the effective cost of leaving home early, the first and last men to depart leave home later and their wives benefit. But since men depart more rapidly during the rush hour, it is possible for some to leave earlier than in the noncooperative regime to the detriment of their wives. It is straightforward to show (see the appendix) that all women end up better off if

$$
-\left(v_{m}^{E}-v_{m}\right)\left(v_{m}^{L}-v_{m}^{M}\right)+\left(v_{m}^{M}-v_{m}\right)^{2}+\left(v_{m}^{M}-v_{m}+v_{m}^{E}-v_{m}\right) \lambda \Delta_{w}>0 .
$$

Condition (42) can be written in terms of costs as

$-\left(1-\frac{\beta_{m}}{\alpha_{m}}\right) \frac{\gamma_{m}}{\alpha_{m}}+1+\left(3-\frac{\beta_{m}}{\alpha_{m}}\right) \frac{\Delta_{m}}{\alpha_{m}}+\left(\frac{\Delta_{m}}{\alpha_{m}}\right)^{2}+\left(2-\frac{\beta_{m}}{\alpha_{m}}+\frac{\Delta_{m}}{\alpha_{m}}\right) \frac{\lambda \Delta_{w}}{\alpha_{m}}>0$.

All terms on the left-hand side are positive except the first which decreases with $\gamma_{m}$. Thus, all women benefit if the cost of arriving late for men is not too large. With the benchmark parameter values, (43) is satisfied as long as $\Delta_{m}>0$ or $\lambda \Delta_{w}>0$. If (43) is not satisfied, then some women are worse off (and their spouses are too).

Eq. (26) can be used to determine whether women are better or worse off on 
average. Subtracting eq. (26) with $\lambda=0$ from eq. (26) with $\lambda>0$ one obtains

$$
\begin{gathered}
\Delta \bar{U}_{w}^{N C} \equiv \bar{U}_{w}^{C}-\bar{U}_{w}^{N}= \\
\lambda \frac{\Delta_{w}^{2}\left(3\left(v_{m}^{M}-v_{m}\right)\left(v_{m}^{M}+\lambda \Delta_{w}-v_{m}\right)-\left(v_{m}^{L}-v_{m}\right)\left(v_{m}^{E}-v_{m}\right)\right)}{2\left(v_{m}^{M}-v_{m}\right)\left(v_{m}^{M}+\lambda \Delta_{w}-v_{m}\right)\left(v_{m}^{L}-v_{m}^{E}\right)} \phi_{m} .
\end{gathered}
$$

The condition for average utility to increase is

$$
\begin{gathered}
\Delta \bar{U}_{w}^{N C}>0 \Longleftrightarrow \\
3\left(v_{m}^{M}-v_{m}\right)\left(v_{m}^{M}+\lambda \Delta_{w}-v_{m}\right)-\left(v_{m}^{L}-v_{m}\right)\left(v_{m}^{E}-v_{m}\right)>0,
\end{gathered}
$$

which can be written in terms of costs as

$$
\begin{gathered}
\Delta \bar{U}_{w}^{N C}>0 \Longleftrightarrow \Gamma_{w}^{N C} \equiv \\
\frac{\beta_{m}}{\alpha_{m}}-\left(1-\frac{\beta_{m}}{\alpha_{m}}\right) \frac{\gamma_{m}}{\alpha_{m}}+2+3 \frac{\Delta_{m}}{\alpha_{m}}+3\left(1+\frac{\Delta_{m}}{\alpha_{m}}\right) \frac{\Delta_{m}+\lambda \Delta_{w}}{\alpha_{m}}>0 .
\end{gathered}
$$

Condition (46) is less stringent than condition (41) or condition (42), and it is satisfied with the benchmark parameter values. Thus, as might be expected, when spouses cooperate, women are more likely to benefit in aggregate than men. Nevertheless, cooperation can leave women worse off if late arrival is sufficiently costly for men. As noted above, the reason is that men depart more quickly once the travel period begins (cf. eq. (19)). If late arrival is very costly for men, cooperation postpones the first departure only slightly and the accelerated departure rate thereafter results in an earlier average departure time.

\subsection{Utility of couples}

Let $\Delta \bar{U}_{c}^{N C}$ denote the average difference in utility for couples between the cooperative and noncooperative equilibria. The effects of cooperation on the average utilities of men and women are given by eqs. (39) and (44) respectively. Adding these equations yields:

$$
\begin{gathered}
\Delta \bar{U}_{c}^{N C} \equiv \bar{U}_{c}^{C}-\bar{U}_{c}^{N} \stackrel{s}{=} \\
\left(v_{m}^{M}+\Delta_{w}-v_{m}\right)\left[\left(v_{m}^{M}-v_{m}\right)^{2}-\left(v_{m}^{E}-v_{m}\right)\left(v_{m}^{L}-v_{m}\right)+2\left(v_{m}^{M}-v_{m}\right) \Delta_{w}\right] \\
-\left(v_{m}^{M}-v_{m}\right)(1-\lambda)(2-\lambda) \Delta_{w}^{2} .
\end{gathered}
$$

Average utility for couples clearly increases if it increases for both sexes as per (40) and (45). With balanced cooperation $(\lambda=1)$, the second line of $(47)$ is zero and condition (47) can be written in terms of unit costs as

$$
\begin{gathered}
(\text { with } \lambda=1:) \quad \Delta \bar{U}_{c}^{N C}>0 \Longleftrightarrow \\
\frac{\beta_{m}}{\alpha_{m}}-\left(1-\frac{\beta_{m}}{\alpha_{m}}\right) \frac{\gamma_{m}}{\alpha_{m}}+2 \frac{\Delta_{m}}{\alpha_{m}}+\left(\frac{\Delta_{m}}{\alpha_{m}}\right)^{2}+2\left(1+\frac{\Delta_{m}}{\alpha_{m}}\right) \frac{\Delta_{w}}{\alpha_{m}}>0 .
\end{gathered}
$$


Couples are more likely to benefit from balanced cooperation if late arrival is not too costly and if both spouses have a large marital premium. With the benchmark values of $\beta_{m} / \alpha_{m}$ and $\gamma_{m} / \alpha_{m}$, and $\Delta_{w}=\Delta_{m}$, (48) is satisfied for $\Delta_{m} / \alpha_{m}>0.115$.

The results of this subsection are summarized in:

Proposition 3 (Benefits of cooperation) Suppose that couples begin to cooperate. Men who depart near the beginning of the rush hour are better off, and men who depart near the end are worse off. As a group, men can be better or worse off. Wives of men who depart near the beginning or end of the rush hour are better off, and it is possible for all women to be better off. Women as a group are always better off if men are better off, but it is possible for both sexes to lose. Couples are more likely to benefit overall if their marital premiums are strong.

The results of this section reveal that the effects of cooperation between couples are rather complex, and depend on the values of several parameters. Some individuals always gain, but in the aggregate it is possible for losses to outweigh the gains.

\section{Empirical evidence on preferences}

\subsection{Empirical results}

In order to estimate the parameters defining couple's trip-timing preferences we designed a survey, MIMETTIC, which was administered in 2011 and 2012 by TNS-SOFRES, a large international survey company, on a sample of 5,210 individuals including 1,047 couples. All the respondents lived in the Greater Paris region (Ile-de-France). ${ }^{14}$ The questionnaire comprised three parts. Part 1 described the household. Part 2 was an individual questionnaire to be completed separately by the main respondent and (if applicable) by his/her spouse. Part 3 was restricted to couples in which both spouses had completed the individual questionnaire. Part 3 was completed a few days after the first two parts, and could be completed by spouses either separately or together.

We focus here on Part 3 of the questionnaire which featured hypothetical scenarios designed to measure the value of time of each spouse at home before the morning commute, either alone or with the spouse present. (To the best of our knowledge, this is the first survey to estimate such value of time differentials.) These stated preference questions were designed on the basis of actual trips in terms of mode, trip purpose, departure time and travel time. Commuting trips

\footnotetext{
${ }^{14}$ The survey was financed by the French Ministry of Transport and Sustainable Development Agency, under the two Predit projects 09 MT CV 13 and 09 MT CV 14. The content of the survey is described in the annex to the report of project $09 \mathrm{MT} \mathrm{CV} \mathrm{13,} \mathrm{available} \mathrm{at} \mathrm{http://temis.documentation.developpement-}$ durable.gouv.fr/documents/Temis/0076/Temis-0076535/20339_A.pdf. (Picard and de Palma, 2012).
} 
were oversampled. An example of a scenario as presented to survey participants is as follows:

"Consider your commuting trip by car. You left at 7:30. Assume you will have a similar trip, in similar conditions, except concerning departure time and travel time. We ask you to imagine that your spouse leaves far before you so that, whatever the case, you are alone when you leave. You have the choice between two alternatives. Which one do you prefer?

Alternative 1: You leave at 7:30 $\left(t_{1}^{d}\right)$ and your travel time is 30 minutes $\left(t t_{1}\right)$.

Alternative 2: You leave at 7:45 $\left(t_{2}^{d}\right)$ and your travel time is 40 minutes $\left(t t_{2}\right) . "$

Consider a person living alone who arrives at work early, and denote travel time in scenario $i$ by $t t_{i}$. Given eq. (3), indifference between Alternatives 1 and 2 corresponds to:

$$
\begin{array}{ccc} 
& \left(v^{I}-v\right) t_{1}^{d}+\left(v-v^{E}\right)\left(t_{1}^{d}+t t_{1}\right)+v^{E} t^{*}+v^{W}\left(T-t^{*}\right) \\
& =\left(v^{I}-v\right) t_{2}^{d}+\left(v-v^{E}\right)\left(t_{2}^{d}+t t_{2}\right)+v^{E} t^{*}+v^{W}\left(T-t^{*}\right) \\
\Leftrightarrow & \left(v^{I}-v\right) t_{1}^{d}+\left(v-v^{E}\right)\left(t_{1}^{d}+t t_{1}\right)=\left(v^{I}-v\right) t_{2}^{d}+\left(v-v^{E}\right)\left(t_{2}^{d}+t t_{2}\right) \\
\Leftrightarrow & \left(v^{I}-v^{E}\right) t_{1}^{d}+\left(v-v^{E}\right) t t_{1}=\left(v^{I}-v^{E}\right) t_{2}^{d}+\left(v-v^{E}\right) t t_{2} \\
\Leftrightarrow & \left(v^{E}-v\right)\left(t t_{2}-t t_{1}\right)=\left(v^{I}-v^{E}\right)\left(t_{2}^{d}-t_{1}^{d}\right) \\
\Leftrightarrow & \frac{v^{I}-v^{E}}{v^{E}-v}=\frac{t t_{2}-t t_{1}}{t_{2}^{d}-t_{1}^{d}} .
\end{array}
$$

The individual prefers alternative 1 if $\frac{v^{I}-v^{E}}{v^{E}-v}<\frac{t t_{2}-t t_{1}}{t_{2}^{d}-t_{1}^{d}}$, and alternative 2 if $\frac{v^{I}-v^{E}}{v^{E}-v}>\frac{t t_{2}-t t_{1}}{t_{2}^{d}-t_{1}^{d}}$. Given Assumption 1, $v^{I}>v^{E}>v$ and the left-hand side of the last equality is positive. Hence, as long as $t_{2}^{d}-t_{1}^{d}>0$ and $t t_{2}-t t_{1}>0$, there exists a user with valid preferences who is indifferent between the two alternatives.

A second question was asked - the content of which depended on the answer to the first question. The travel times and departure times used in the second question are indexed by 3 and 4 if alternative 1 was selected in the first question, and by 5 and 6 if alternative 2 was selected in the first question. Travel times and departure times were selected around the actual travel time and departure time so that the scenario was plausible for the respondent. They were selected randomly in order to solve the endogeneity problem explained in de Palma and Picard (2005). The experiment was designed such that $\frac{t t_{4}-t t_{3}}{t_{4}^{d}-t_{3}^{d}}<\frac{t t_{2}-t t_{1}}{t_{2}^{d}-t_{1}^{d}}<$ $\frac{t t_{6}-t t_{5}}{t_{6}^{d}-t_{5}^{d}}$ in all scenarios (and such that the respondent was always alone when $\mathrm{s} /$ he left home). The answers to the two questions established upper and/or lower bounds on the ratio $\frac{v^{I}-v^{E}}{v^{E}-v}$. Four cases could arise.

- The respondent selected alternative 1 for the first question and alternative 3 for the second question. Then $\frac{v^{I}-v^{E}}{v^{E}-v}<\frac{t t_{4}-t t_{3}}{t_{4}^{d}-t_{3}^{d}}$.

- The respondent selected alternative 1 for the first question and alternative 4 for the second question. Then $\frac{t t_{4}-t t_{3}}{t_{4}^{d}-t_{3}^{d}}<\frac{v^{I}-v^{E}}{v^{E}-v}<\frac{t t_{2}-t t_{1}}{t_{2}^{d}-t_{1}^{d}}$. 
- The respondent selected alternative 2 for the first question and alternative 5 for the second question. Then $\frac{t t_{2}-t t_{1}}{t_{2}^{d}-t_{1}^{d}}<\frac{v^{I}-v^{E}}{v^{E}-v}<\frac{t t_{6}-t t_{5}}{t_{6}^{d}-t_{5}^{d}}$.

- The respondent selected alternative 2 for the first question and alternative 6 for the second question. Then $\frac{t t_{6}-t t_{5}}{t_{6}^{d}-t_{5}^{d}}<\frac{v^{I}-v^{E}}{v^{E}-v}$.

The second question was not asked when it would have generated values too close to the values of the first question since the respondent might have been unable to perceive the difference between the questions. In such instances, the only conclusion that could be drawn was either $\frac{v^{I}-v^{E}}{v^{E}-v}<\frac{t t_{2}-t t_{1}}{t_{2}^{d}-t_{1}^{d}}$ or $\frac{v^{I}-v^{E}}{v^{E}-v}>$ $\frac{t t_{2}-t t_{1}}{t_{2}^{d}-t_{1}^{d}}$.

We used an ordered logit-type model to estimate the value of $\frac{v^{I}-v^{E}}{v^{E}-v}$ for each sex. ${ }^{15}$ This model was extended as described in Picard and Wolff (2010) to accommodate missing information when the second question was not asked.

A similar procedure was used to estimate the value of time with a spouse present, $\frac{v^{M}-v^{E}}{v^{E}-v}$. In this case, all the departure times used in the three questions were such that the spouse was still present when the respondent was supposed to leave, in all the alternatives of the corresponding scenarios. An example of the wording is as follows:

"Consider your commuting trip by car. You left at 7:30. Assume you will have a similar trip, in similar conditions, except concerning departure time and travel time. We ask you to imagine that your spouse leaves far after you so that, whatever the case, she is at home with you when you leave. You have the choice between two alternatives. Which one do you prefer?"

We used a sub-sample of 327 women and 369 men without children, who both commuted either by car or by public transit the day before the survey, and answered the relevant hypothetical scenarios. In this sample, the man left before the woman in $62 \%$ of cases, the man and woman left at the same time in $4 \%$ of cases, and the woman left before the man in the remaining $34 \%$ of cases.

Consistent with the theoretical model described above, parameters are assumed homogeneous in the male population, and homogeneous in the female population. More precisely, we assume that $\frac{v^{I}-v^{E}}{v^{E}-v}$ (resp. $\frac{v^{M}-v^{E}}{v^{E}-v}$ ) is an individualspecific random (gaussian) variable with gender-specific expectation. The estimated parameters thus correspond to the average values of $\frac{v^{I}-v^{E}}{v^{E}-v}$ and $\frac{v^{M}-v^{E}}{v^{E}-v}$

\footnotetext{
${ }^{15}$ The fact that the departure and travel times considered in the second question depend on the answer to the first question would induce an endogeneity bias if we used a simple binary logit model to analyze the answer to the second question. de Palma and Picard (2005) show that this bias, which can be very large, can be corrected by using an ordered-logit type model. de Palma, Picard and Ziegelmeyer (2011) show that combining a tree structure to ask questions, and applying an ordered logit (or probit) model, improves the accuracy of the results compared to using one-stage questions and a simple binary logit model.
} 
in the male and female populations. We estimated the parameters assuming that $\frac{v^{I}-v^{E}}{v^{E}-v}$ and $\frac{v^{M}-v^{E}}{v^{E}-v}$ are independent of each other, as well as independent between spouses. We then checked the robustness of the results to the correlation between the two parameters as well as between spouses. For this last series of estimates, the sample was reduced to the 227 couples in which both spouses answered the two questions. Parameters are estimated using maximum likelihood. The individual-specific likelihood corresponds to the probability of the answer selected by the respondent. When parameters are assumed independent, the four ratios can be estimated separately (i.e., $\frac{v^{I}-v^{E}}{v^{E}-v}$ and $\frac{v^{M}-v^{E}}{v^{E}-v}$ in the male and female populations). Let $\Phi$ denote the c.d.f. of a normal distribution with zero-mean and gender-specific variance, estimated simultaneously with the other parameters. The individual-specific likelihood is given by:

- $\mathbb{P}\left(\frac{v^{I}-v^{E}}{v^{E}-v}<\frac{t t_{4}-t t_{3}}{t_{4}^{d}-t_{3}^{d}}\right)=\Phi\left(\frac{t t_{4}-t t_{3}}{t_{4}^{d}-t_{3}^{d}}\right)$ if the respondent selected alternative 1 for the first question and alternative 3 for the second question.

- $\mathbb{P}\left(\frac{t t_{4}-t t_{3}}{t_{4}^{d}-t_{3}^{d}}<\frac{v^{I}-v^{E}}{v^{E}-v}<\frac{t t_{2}-t t_{1}}{t_{2}^{d}-t_{1}^{d}}\right)=\Phi\left(\frac{t t_{2}-t t_{1}}{t_{2}^{d}-t_{1}^{d}}\right)-\Phi\left(\frac{t t_{4}-t t_{3}}{t_{4}^{d}-t_{3}^{d}}\right)$ if the respondent selected alternative 1 for the first question and alternative 4 for the second question.

- $\mathbb{P}\left(\frac{t t_{2}-t t_{1}}{t_{2}^{d}-t_{1}^{d}}<\frac{v^{I}-v^{E}}{v^{E}-v}<\frac{t t_{6}-t t_{5}}{t_{6}^{d}-t_{5}^{d}}\right)=\Phi\left(\frac{t t_{6}-t t_{5}}{t_{6}^{d}-t_{5}^{d}}\right)-\Phi\left(\frac{t t_{2}-t t_{1}}{t_{2}^{d}-t_{1}^{d}}\right)$ if the respondent selected alternative 2 for the first question and alternative 5 for the second question.

- $\mathbb{P}\left(\frac{t t_{6}-t t_{5}}{t_{6}^{d}-t_{5}^{d}}<\frac{v^{I}-v^{E}}{v^{E}-v}\right)=1-\Phi\left(\frac{t t_{6}-t t_{5}}{t_{6}^{d}-t_{5}^{d}}\right)$ if the respondent selected alternative 2 for the first question and alternative 6 for the second question.

- $\mathbb{P}\left(\frac{v^{I}-v^{E}}{v^{E}-v}<\frac{t t_{2}-t t_{1}}{t_{2}^{d}-t_{1}^{d}}\right)=\Phi\left(\frac{t t_{2}-t t_{1}}{t_{2}^{d}-t_{1}^{d}}\right)$ if the respondent selected alternative 1 for the first question and was not asked a second question.

- $\mathbb{P}\left(\frac{v^{I}-v^{E}}{v^{E}-v}>\frac{t t_{2}-t t_{1}}{t_{2}^{d}-t_{1}^{d}}\right)=1-\Phi\left(\frac{t t_{2}-t t_{1}}{t_{2}^{d}-t_{1}^{d}}\right)$ if the respondent selected alternative 2 for the first question and was not asked a second question.

The extension to correlated parameters is straightforward but more cumbersome. It relies on the c.d.f. of a multivate normal.

The estimates were very similar with and without correlations, so we selected the most efficient estimates (obtained in a larger sample) assuming no correlation. These are reported in Table 1

The estimates for the value of time late (i.e., $\frac{v^{L}-v^{I}}{v^{I}-v^{E}}$ ) were obtained from a previous survey, MADDIF, using the same methodology as the one used in MIMETTIC. This ratio was estimated jointly for men and women since no significant differences by gender were found. Combining the results of the two 


\begin{tabular}{llcc}
\hline \hline & & men & women \\
\hline \hline Correlated & $\frac{v^{M}-v^{E}}{v^{E}-v}=\frac{\beta^{M}}{\alpha^{M}-\beta^{M}}$ & 0.8421 & 0.5817 \\
& $\frac{v^{I}-v^{E}}{v^{E}-v}=\frac{\beta^{I}}{\alpha^{I}-\beta^{I}}$ & 0.4563 & 0.5347 \\
Independent & $\frac{v^{M}-v^{E}}{v^{E}-v}=\frac{\beta^{M}}{\alpha^{M}-\beta^{M}}$ & 0.7074 & 0.5470 \\
& $\frac{v^{I}-v^{E}}{v^{E}-v}=\frac{\beta^{I}}{\alpha^{I}-\beta^{I}}$ & 0.4741 & 0.5004
\end{tabular}

Table 1: Parameter estimates: independent and correlated parameters

surveys (assuming independence of the parameters), we obtain three ratios for each gender. The results are reported in Table 2.

\begin{tabular}{lcc}
\hline \hline & men & women \\
\hline \hline$\frac{v^{L}-v^{I}}{v^{I}-v^{E}}=\frac{\gamma^{I}}{\beta^{I}}$ & 1.5941 & 1.5941 \\
$\frac{v^{M}-v^{E}}{v^{E}-v}=\frac{\beta^{M}}{\alpha^{M}-\beta^{M}}$ & 0.7074 & 0.5470 \\
$\frac{v^{I}-v^{E}}{v^{E}-v}=\frac{\beta^{I}}{\alpha^{I}-\beta^{I}}$ & 0.4741 & 0.5004
\end{tabular}

Table 2: Parameter estimates

No constraint was imposed on the parameters to be estimated. Nevertheless, the estimated values for $\frac{v^{I}-v^{E}}{v^{E}-v}, \frac{v^{M}-v^{E}}{v^{E}-v}$, and the marital premiums were all positive, consistent with the rankings in (2) and (18). Given the estimates in Table 2, parameters of interest are easily computed. For example, $\frac{\beta_{m}^{I}}{\alpha_{m}^{I}-\beta_{m}^{I}}=$ $\frac{\frac{1}{\alpha_{m}}-1}{\beta_{m}}=0.4741$. Hence $\frac{\alpha_{m}}{\beta_{m}}=\frac{1}{0.4741}+1=3.1093$ and $\frac{\beta_{m}}{\alpha_{m}}=\frac{1}{3.1093}=0.32162$. The other estimates are $\gamma_{m} / \alpha_{m}=0.51269, \Delta_{m} / \alpha_{m}=0.1583$, and $\Delta_{w} / \alpha_{m}=$ 0.0311 .

\subsection{Application of the estimates}

In this subsection we apply the parameter estimates to the formulas derived in Sections 2 to 5. Without affecting results of interest, we normalize men's work-start time to $t_{m}^{*}=0$, and set $\phi_{m}=2$ so that the departure period lasts for 2 hours. We also set $\alpha_{m}$ to $€ 10$. The results are shown in Table 3 .

Panel (a): If men live alone, they depart during the time interval $\left[t_{0 m}^{I}, t_{e m}^{I}\right]=$ $[-1.23,0.77]$ so that a little over three-fifths arrive at work early. The cost of congestion per commuter is about $€ 4$.

Panel (b): In the noncooperative equilibrium after marriage, men depart during the time interval $\left[t_{0 m}^{N}, t_{e m}^{N}\right]=[-0.85,1.15]$ which is about 23 mins later than before marriage. The cost of congestion rises by about $€ 0.12$. Women incur only a slight cost from congestion on the men's route of $€ 0.008$. The 
cost is small because women's marital premium is small, and men's average departure time turns out to be only about 1.5 mins later than when they are single. In the balanced cooperative equilibrium, departures begin about 4 mins later still. Congestion costs for men drop by about $€ 0.10$, and women actually benefit slightly from the congestion because men leave home after $t_{m}^{*}$ on average. In summary, marriage raises the costs of congestion moderately on the men's route when men do not cooperate, but most of the extra cost is eliminated in the case of balanced cooperation.

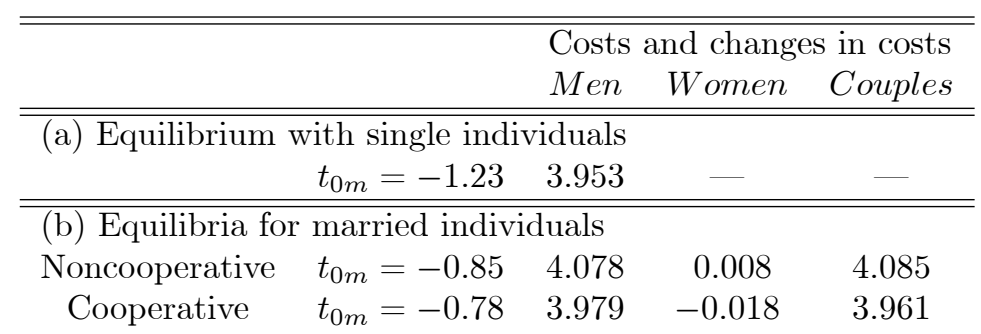

Table 3: Costs and efficiency gains for numerical example

The results in Table 3 pertain only to one particular set of parameter values. Figures 3 and 4 present a more comprehensive view of how the the marital premiums influence the benefits of cooperation. Figure 3 depicts the effects of marriage on utilities in the noncooperative equilibrium. Both sexes are worse off if $\Delta_{m}$, the marital premium of men, is less than about 17 percent of men's VOT. For slightly larger values of $\Delta_{m}$ women benefit $(W)$, then women and couples $(W, C)$, and finally men as well $(M, W, C)$. The point estimates of $\Delta_{m} / \alpha_{m}=0.1583$ and $\Delta_{w} / \alpha_{m}=0.0311$ shown by the black dot lie close to the transition zone so that the utility losses reported in Table 3 are rather tenuous. Figure 4 shows the effects of cooperation on utilities. Women and couples benefit for all values of $\Delta_{m} / \alpha_{m}$ and $\Delta_{w} / \alpha_{m}$. Men benefit as well if their marital premium is not too small compared to women's.

The estimates of $\beta_{m} / \alpha_{m}=0.32162$ and $\gamma_{m} / \alpha_{m}=0.51269$ from our study are smaller than for most earlier studies, and the low value of $\gamma_{m} / \alpha_{m}$ is atypical. To assess the robustness of the results, the analysis is repeated using the benchmark parameter values $\beta_{m} / \alpha_{m}=0.5$ and $\gamma_{m} / \alpha_{m}=2$ considered earlier. Results are shown in Figures 5 and 6 . Figure 5 reveals that the effects of marriage are much less favorable than with the new estimates since neither sex benefits unless $\Delta_{m} / \alpha_{m}$ exceeds about 1.1. Although theoretically possible, such high values seem implausible. Cooperation is also less beneficial than with the new estimates (compare Figure 6 with Figure 4) although the difference is modest. For very small values of $\Delta_{m} / \alpha_{m}$ and $\Delta_{w} / \alpha_{m}$, women gain slightly from cooperation but men lose by more so that couples end up worse off. 


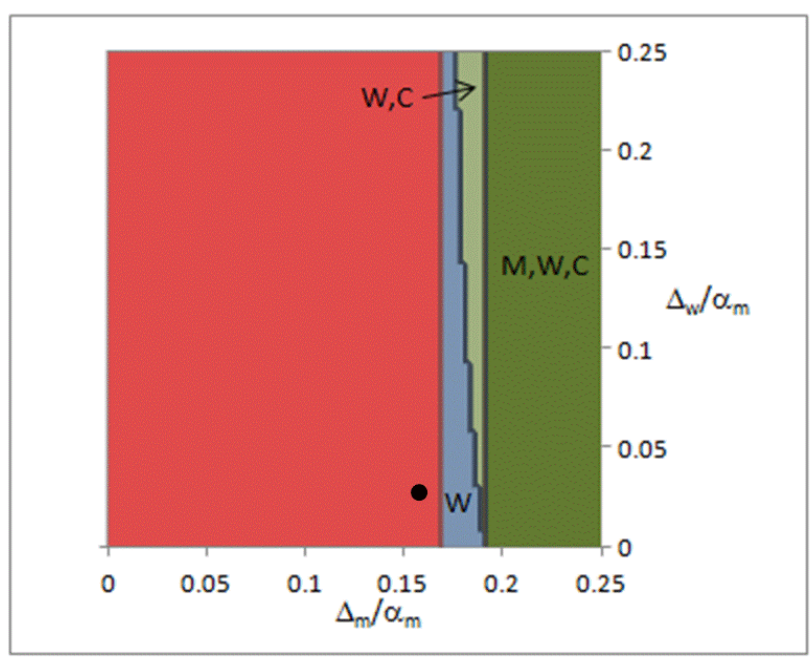

Figure 3: Who gains in transition from single to noncooperative couples equilibrium: New parameter estimates

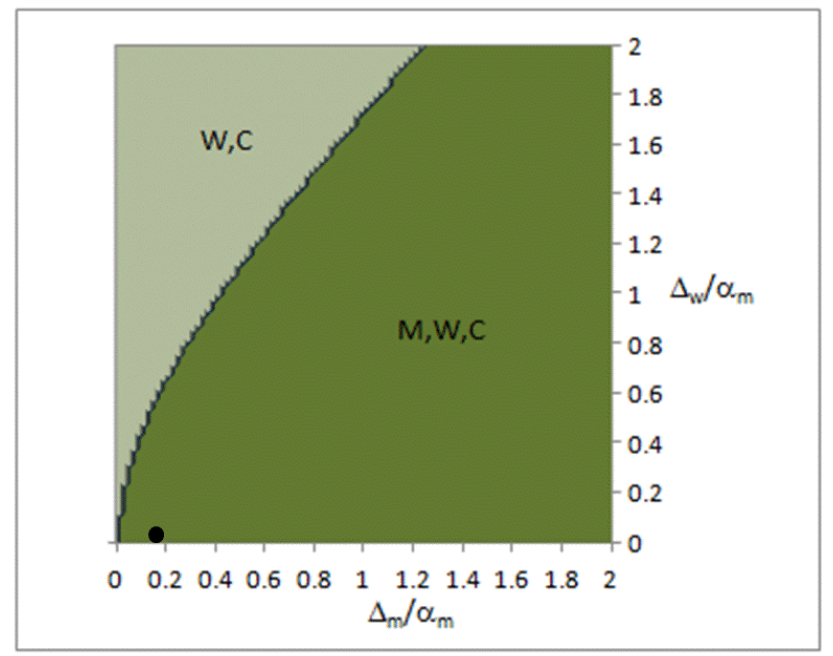

Figure 4: Who gains in transition from noncooperative to cooperative couples equilibrium: New parameter estimates 


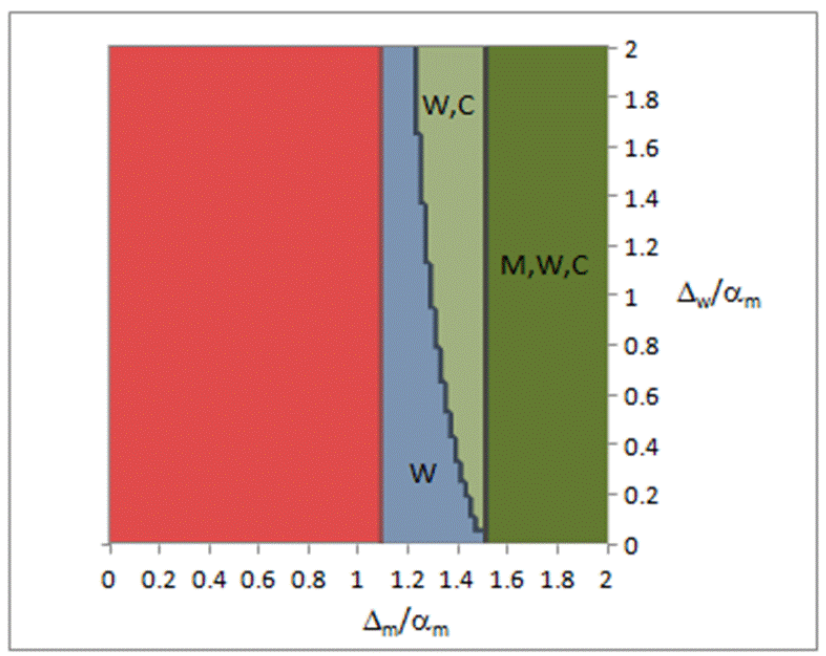

Figure 5: Who gains in transition from single to noncooperative couples equilibrium: Benchmark parameters

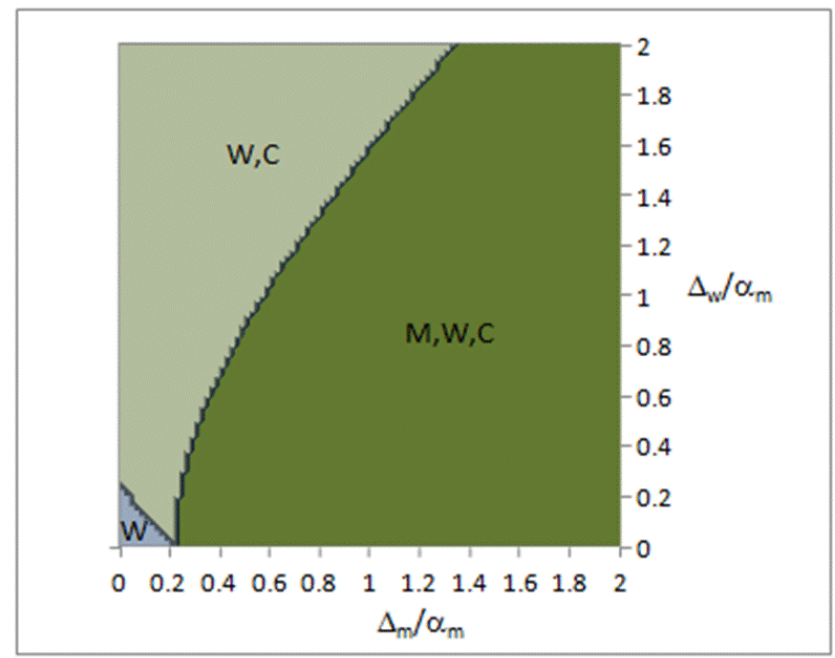

Figure 6: Who gains in transition from noncooperative to cooperative couples equilibrium: Benchmark parameters 


\section{Conclusions}

This paper has examined the evolution of traffic congestion when trip-timing decisions are made by family members with interdependent preferences. We consider the specific case of couples who value time at home more when they are together than when alone. The additional utility or "marital premium" may differ between the sexes. One spouse (assumed to be the man) leaves for work first. His marital premium induces him to postpone leaving home. Leaving home later also benefits his wife. The degree to which the man accounts for this departure-time externality is characterized by a nonnegative Pareto weight. No cooperation corresponds to the limiting case of 0 , and balanced cooperation to a value of 1 . The man is assumed not to derive utility from his wife's utility per se. ${ }^{16}$

Our analysis focuses on how the costs of traffic congestion are affected by the changes in trip-timing preferences induced by marriage. Two main conclusions emerge. First, the costs of congestion can be higher for both sexes in the noncooperative-couples equilibrium than in the equilibrium with single individuals. Costs increase for men because the opportunity cost per minute of arriving early at work increases proportionally more than the opportunity cost per minute of late arrival falls. Costs increase for women because congestion induces men to leave home earlier on average, and thus spend less time at home.

Second, cooperation has mixed effects on welfare. Men who depart near the beginning of the rush hour are better off, and men who depart near the end are worse off. As a group, men can be better or worse off. Wives of men who depart near the beginning or end of the rush hour are better off. It is possible for all women to be better off, but also possible for them to be worse off on average. Moreover, both members of a couple can lose. Couples are more likely to benefit overall if their marital premiums are strong.

A notable feature of our paper is that schedule coordination affects traffic congestion and utility even though coordination occurs only within couples who each contribute a negligible portion (i.e., measure zero) of total travel demand. This contrasts with studies of atomic congestion games in which individual users such as major freight shippers control a positive fraction of total traffic, and have incentive to internalize the congestion costs their traffic imposes on itself.

Our analysis has focused on how marriage affects traffic congestion rather than overall household utility. A more general assessment of the effects of marriage, as well as other household decisions, could be undertaken using an extension of the household activity framework adopted here. Indeed, there are various avenues for further research. A particularly restrictive assumption in our model is that men and women do not use the same commuting route, and hence do not interfere with each other on the roads. An alternative is the opposite extreme in which men and women use the same route. However, this

\footnotetext{
${ }^{16}$ The man is thus assumed to have nondeferential preferences. It can be shown that the man's departure time in our model is the same as if he had caring preferences, and $\lambda$ represents his degree of altruism, that is the weight he attaches to his wife's utility. These two models of interaction within couples differ only in terms of welfare analysis.
} 
setting is much more complicated to analyze than separate routes even if men and women are assumed to have the same marital premium and other utility parameters - which is not the case for our empirical estimates. ${ }^{17}$

One important dimension of behavior omitted from the model is the care of children which can be challenging if both spouses work outside the home. Couples must decide who takes the children to school and when, who brings them back home, and who transports them to out-of-school activities. A parent has to trade off not only his/her schedule convenience with that of his/her spouse, but also the schedules of children. Traditionally, women have borne the lion's share of child-care and other household responsibilities. Although men are gradually shouldering more of the burden, employed women still face tighter time constraints, and this is one reason why they tend to work closer to home (Turner and Niemeier, 1997) and exhibit different travel patterns than men (Schintler, 2001).

Another limitation of the model is that it ignores agglomeration economies at work. Agglomeration economies between workers in the same firm or establishment may be partially or fully internalized by employers, but they are likely to remain largely uninternalized between institutions. As Fosgerau and Small (2014) show, agglomeration economies at work or at home increase the cost of congestion and the corresponding benefits from congestion pricing.

In our model congestion pricing of the men's commuting route would affect not only the men who use it, but also their spouses because of changes in men's departure-time decisions. Expanding bottleneck capacity on the men's route $\left(s_{m}\right)$ would have spillover effects as well. These effects are relatively easy to discern. Before marriage, the cost of congestion for men is given by $C_{m}^{I}$ in eq. (17). The marginal benefit of capacity expansion per man is $\partial C_{m}^{I} / \partial s_{m}=$ $C_{m}^{I} / s_{m}$. After marriage, the cost of congestion is given by $C_{m}^{N}$ in eq. (28), and the marginal benefit of capacity expansion per man is $\partial C_{m}^{N} / \partial s_{m}=C_{m}^{N} / s_{m}$. Expanding capacity is therefore more beneficial for men after marriage if $C_{m}^{N}>$ $C_{m}^{I}$; i.e. when the condition identified in Prop. 1 is violated. For women, expanding $s_{m}$ is beneficial if congestion on the men's route leaves women worse off; i.e. if $\Delta \bar{U}_{w}^{I N}<0$ or the condition identified in Prop. 2 is violated. In a similar way, the benefits of capacity expansion for men and women in the cooperative equilibrium can be compared with the benefits in the noncooperative equilibrium using conditions (41) and (46) respectively.

Another limitation of the model is that it is restricted to the morning commute. The evening commute is arguably as important as the morning commute, and including the evening would extend the model closer to a full day of household activity. If morning and evening commute timing decisions are assumed to be independent, a model of the evening parallel to the morning model here can be used. Preliminary analysis of the model indicates that the results are

\footnotetext{
${ }^{17}$ If men and women commute on the same route, and have the same marital premium, the size of the premium determines both the order in which individuals depart and whether spouses leave home at the same time. The qualitative pattern of departures changes several times as the premium increases.
} 
very similar. ${ }^{18}$ We offer a sketch here. Let $v^{E}$ denote the cost per minute of leaving work early, and $v^{L}$ the value of time spent at work late. Other utility parameters are defined as for the morning. The parameter ranking for each sex becomes $v^{E}>v^{M} \geq v^{I}>v^{L}>v$. For a married person the unit cost of leaving work early in the evening is $\beta^{e v e}=v^{E}-v^{M}$, and the unit cost of leaving late is $\gamma^{e v e}=v^{M}-v^{L}$. In the morning model it is assumed that men leave home for work earlier than women (if women work out of home at all). If the two sexes have similar work hours, men will return home first in the evening and the departure times of women from work will affect the utility of men. The marital premium now reduces the opportunity cost of leaving work early for women, and increases their opportunity cost of leaving late. Empirical evidence is scant, but it is reasonable to assume that $\beta^{\text {eve }}>\gamma^{\text {eve }}$. Just as in the morning model, marriage brings the costs of early and late departure into closer balance. All the qualitative results derived in the paper for the morning commute then carry over to the evening commute.

\section{Role of the funding source}

This research has been conducted as part of the project Labex MME-DII (ANR11LBX-0023-01). de Palma and Picard benefitted from the financial support of PREDIT (projects 09 MT CV 13 and 09 MT CV 14) and Agence Nationale de la Recherche (ELITISME project). Lindsey would like to thank the Social Sciences and Humanities Research Council of Canada for financial support. PREDIT, ANR and SSHRC were not involved in any specific aspects of this paper or in the decision to submit it for publication.

\section{Acknowledgments}

We would like to thank participants at the Workshop on the Economics of Couples, Theory and Applications, December 2009, and in particular, Pierre-André Chiappori and Bob Pollak. For useful comments we are also grateful to participants at the 57th Annual North American Meetings of the Regional Science Association International in Denver, November 2010. Sophie Dantan provided invaluable help with the empirical analysis. Any errors are our responsibility.

\footnotetext{
${ }^{18}$ The evening commute has been studied using the bottleneck model by a few authors (de Palma and Lindsey, 2002a, 2002b; Fargier, 1983; Vickrey, 1973; Zhang et al, 2008; Zhang et al., 2005). With identical, independent users, equilibrium for the evening is a mirror image of the morning. However, the symmetry breaks down if users differ in their preferred arrival times and travel on the same route (de Palma and Lindsey, 2002a, 2002b).
} 


\section{References}

[1] Becker, G. S. (1974). A Theory of Social Interactions, Journal of Political Economy 82(6), 1063-93.

[2] Becker, G.S. (1991) A Treatise on the Family, enlarged edition, Harvard University Press, Cambridge.

[3] Bhat, C. R. and R. M. Pendyala (2005), Modeling intra-household interactions and group decision-making, Transportation 32, 443-448.

[4] Bradley, M. and P. Vovsha (2005), A model for joint choice of daily activity pattern types of household members, Transportation 32, 545-571.

[5] Chiappori P.-A. (1992), Collective labor supply and welfare, The Journal of Political Economy 100, 437-467.

[6] Chiappori, P.-A. (1998), Rational household labor supply, Econometrica $56,63-90$.

[7] Chiappori, P.-A., A. de Palma and N. Picard (2011), Couple residential location and spouses' workplaces, Mimeo.

[8] de Palma, A. and M. Fosgerau (2011), Dynamic traffic modeling, in A. de Palma, R. Lindsey, E. Quinet and R. Vickerman (eds.), Handbook in Transport Economics, Edward Elgar, Cheltenham, UK and Northampton, Mass, USA, 188-212.

[9] de Palma, A. and D. Rochat (1997), The impact of adverse weather conditions on the propensity to change travel decisions: A survey of Brussels commuters, Transportation Research Part A, 31(3), 181-203.

[10] de Palma, A. and R. Lindsey (2002a), Comparison of morning and evening commutes in the Vickrey bottleneck model, Transportation Research Record 1807, 26-33.

[11] de Palma, A. and R. Lindsey (2002b), Congestion pricing in the morning and evening peaks: A comparison using the Bottleneck Model, Proceedings of the 37th Annual Conference of the Canadian Transportation Research Forum: 2002 Transportation Visioning - 2002 and Beyond, Vancouver, May 2002, 179-193.

[12] de Palma A. and N. Picard (2005), Route choice decision under travel time uncertainty, Transportation Research Part A: Policy and Practice, 39(4), 295-324.

[13] de Palma, A., I. Inoa and N. Picard (2014), Discrete choice decision-making with multiple decision makers within the household, in Hess and Daly (eds.), Handbook of Choice Modelling, forthcoming. 
[14] Fargier, P.H. (1983), Effects of the choice of departure time on road traffic congestion: Theoretical approach, Proceedings of the 8th International Symposium on Transportation and Traffic Theory, Toronto, Canada: University of Toronto Press, 223-263.

[15] Fosgerau, M., L. Engelson and J.P. Franklin (2014), Commuting for meetings, Journal of Urban Economics 81(C), 104-113.

[16] Fosgerau, M. and K.A. Small (2014), Endogenous scheduling preferences and congestion, working paper, May 25.

[17] Gubins, S. and E. T. Verhoef (2011), Teleworking and congestion: A dynamic bottleneck analysis, Tinbergen Institute Discussion Paper 11-096/3 (http://ssrn.com/abstract=1888241). A later version appears as Chapter 2 in: Gubins, S. (2014), Information Technologies and Travel, $\mathrm{PhD}$ dissertation, Department of Spatial Economics, VU University Amsterdam, September.

[18] Picard, N. and A. de Palma (2012). Annexe 9.2 : Copies d'écran du questionnaire en ligne, in Trajets et mobilité des ménages : choix individuels et collectifs - Rapport Final du projet PREDIT MEDDTL-ADEME 09 MT CV 13.

[19] Picard, N., A. de Palma and S. Dantan (2013), Intra-household discrete choice models of mode choice and residential location, International Journal of Transport Economics XL(3), 419-445.

[20] Picard, N., A. de Palma and I. Inoa (2014), Intra-household decision models of residential and job location, in M. Bierlaire, A. de Palma, R. Hurtubia and P. Waddell (eds.), Integrated Transport and Land Use Modeling for Sustainable Cities, Ch. 2.4, EPFL Press.

[21] Picard N. and F.C. Wolff (2010), Measuring educational inequalities: A method and an application to Albania, Journal of Population Economics 23(3), 989-1023.

[22] Pinjari, A.R. and C. R. Bhat (2011), Activity-based travel demand analysis, in A. de Palma, R. Lindsey, E. Quinet and R. Vickerman (eds.), Handbook in Transport Economics, Edward Elgar, Cheltenham, UK and Northampton, Mass, USA, 213-248.

[23] Pollak, R. (1988), Tied Transfers and Paternalistic Preferences. American Economic Review 66(3), 309-320.

[24] Pollak, R. (2003), Gary Becker's Contributions to Family and Household Economics. Review of Economics of the Household 1(1), 111-141.

[25] Schintler, L. (2001), Women and travel, in D.A. Hensher and K.J. Button (eds.), Handbook of Transport Systems and Traffic Control 3, Oxford: Elsevier Science, 351-358. 
[26] Small, K. (1982), The scheduling of consumer activities: Work trips. American Economic Review 72(3), 467-479.

[27] Swärdh, J.E. and S. Algers (2010), Willingness to accept commuting time for yourself and for your spouse: Empirical evidence from Swedish stated preference data, paper presented at the 12th World Conference on Transport Research, Lisbon, July 11-15.

[28] Timmermans, H.J.P. and J. Zhang (2009), Modeling household activity travel behavior, Transportation Research Part B, 43, 187-190.

[29] Tseng, Y.Y. and E.T. Verhoef (2008), Value of time by time of day: a stated-preference study, Transportation Research Part B, 42(7-8), 607-618.

[30] Turner, T. and D. Niemeier (1997), Travel to work and household responsibility: New evidence, Transportation 24(4), 397-419.

[31] Vickrey, W.S. (1969), Congestion theory and transport investment, American Economic Review (Papers and Proceedings) 59, 251-261.

[32] Vickrey, W.S. (1973), Pricing, metering, and efficiently using urban transportation facilities, Highway Research Record 476, 36-48.

[33] Zhang, X., H-J. Huang and H. M. Zhang (2008), Integrated daily commuting patterns and optimal road tolls and parking fees in a linear city, Transportation Research Part B 42(1), 38-56.

[34] Zhang, X., H. Yang and H-J. Huang (2005), Integrated scheduling of daily work activities and morning-evening commutes with bottleneck congestion, Transportation Research Part A 39(1), 41-60.

\section{Notational Glossary}

\section{$10.1 \quad$ Numbers of users}

$N$ : number of men, number of women, and number of couples

$N_{E}$ : number of individuals who arrive early

$N_{L}$ : number of individuals who arrive late

$s$ : bottleneck capacity [veh./hr]

$\phi: N / s[\mathrm{hr}]$

\subsection{Preferences}

$t^{*}:$ desired arrival time at work

$U$ : utility

$v^{I}$ : utility from time spent at home alone [per minute]

$v^{M}$ : utility from time spent at home with spouse [per minute]

$v:$ utility from time spent driving [per minute] 
$v^{E}$ : utility from time spent at work before $t^{*}$ [per minute]

$v^{W}$ : utility from time spent at work during regular hours [per minute]

$v^{P}$ : (dis)utility of time missed from work due to late arrival [per minute]

$v^{L}=v^{W}-v^{P}$ : loss of utility from not being at work during regular hours [per minute].

$\Gamma=\left(v_{m}^{I}+v_{m}^{M}\right)-\left(v_{m}^{E}+v_{m}^{L}\right)$

$\Delta=v^{M}-v^{I}$ [per minute]

$\lambda$ : Pareto weight

$\Psi^{I}=\frac{\left(v^{I}-v^{E}\right)\left(v^{L}-v^{I}\right)}{v^{L}-v^{E}}$

$\Psi^{N}=\frac{\left(v_{m}^{M}-v_{m}^{E}\right)\left(v_{m}^{L}-v_{m}^{M}\right)}{v_{m}^{L}-v_{m}^{E}}$

\subsection{Times of day}

$t^{d}:$ departure time from home

$t^{a}$ : arrival time at work

$t_{0}$ : time when first individual leaves home

$t_{e}:$ time when last individual leaves home

$\widetilde{t}$ : departure time for which individual arrives on time

$T$ : end of accounting day

$\bar{t}_{m E}$ : average departure time of men who arrive early

$\bar{t}_{m L}$ : average departure time of men who arrive late

\subsection{Flows and delays}

$C$ : cost of congestion

$r$ : aggregate departure rate from home

$q\left(t^{d}\right)=t^{a}-t^{d}$ : queuing delay $=$ trip duration for trip departing at $t^{d}$

\subsection{Subscripts, superscripts, and regimes}

$E$ : superscript for early arrival

$L$ : superscript for late arrival

$I$ : superscript for individuals

$M$ : superscript for marriage

$c:$ subscript for couples

$m$ : subscript for men

$w:$ subscript for women

$N$ : noncooperative-couples equilibrium

$C$ : cooperative-couples equilibrium 


\section{Appendix}

\subsection{Mean utility of married men}

The mean utility can be calculated using the formula

$$
\bar{U}_{m}^{M}=\frac{N_{m E}}{N} \bar{U}_{m E}^{M}+\frac{N_{m L}}{N} \bar{U}_{m L}^{M}
$$

where $N_{m E}$ is the number of men who arrive early, $N_{m L}$ is the number who arrive late, $\bar{U}_{m E}^{M}$ is the mean utility of men who arrive early, and $\bar{U}_{m L}^{M}$ is the mean utility of men who arrive late. $N_{m E}$ and $N_{m L}$ are given respectively by the counterparts to eqs. (13) and (14):

$$
\begin{aligned}
& N_{m E}=\frac{v_{m}^{L}-v_{m}^{M}-\lambda \Delta_{w}}{v_{m}^{L}-v_{m}^{E}} N, \\
& N_{m L}=\frac{v_{m}^{M}+\lambda \Delta_{w}-v_{m}^{E}}{v_{m}^{L}-v_{m}^{E}} N .
\end{aligned}
$$

Since utilities vary linearly with departure time,

$$
\begin{aligned}
& \bar{U}_{m E}^{M}=\frac{1}{2}\left(U_{m E}\left(t_{0 m}^{M}\right)+U_{m E}\left(\tilde{t}_{m}^{M}\right)\right), \\
& \bar{U}_{m L}^{M}=\frac{1}{2}\left(U_{m E}\left(\tilde{t}_{m}^{M}\right)+U_{m L}\left(t_{e m}^{M}\right)\right) .
\end{aligned}
$$

Substituting eq. (21) in the text for $t_{0 m}^{M}$ into (23) gives

$$
U_{m E}\left(t_{0 m}^{M}\right)=v_{m}^{M} t_{m}^{*}+v_{m}^{W}\left(T_{m}-t_{m}^{*}\right)-\frac{\left(v_{m}^{M}-v_{m}^{E}\right)\left(v_{m}^{L}-v_{m}^{M}-\lambda \Delta_{w}\right)}{v_{m}^{L}-v_{m}^{E}} \phi_{m} .
$$

Substituting (22) for $t_{e m}^{M}$ into (24) gives

$$
U_{m L}\left(t_{e m}^{M}\right)=v_{m}^{M} t_{m}^{*}+v_{m}^{W}\left(T_{m}-t_{m}^{*}\right)-\frac{\left(v_{m}^{M}-v_{m}^{E}+\lambda \Delta_{w}\right)\left(v_{m}^{L}-v_{m}^{M}\right)}{v_{m}^{L}-v_{m}^{E}} \phi_{m} .
$$

On-time departure time, $\tilde{t}_{m}^{M}$, is given by the counterpart to eq. (12):

$$
\tilde{t}_{m}^{M}=t_{m}^{*}-\frac{\left(v_{m}^{M}+\lambda \Delta_{w}-v_{m}^{E}\right)\left(v_{m}^{L}-v_{m}^{M}-\lambda \Delta_{w}\right)}{\left(v_{m}^{M}+\lambda \Delta_{w}-v_{m}\right)\left(v_{m}^{L}-v_{m}^{E}\right)} \phi_{m}
$$

Using (51), (19), and (23) yields

$U_{m E}\left(\widetilde{t}_{m}^{M}\right)=v_{m}^{M} t_{m}^{*}+v_{m}^{W}\left(T_{m}-t_{m}^{*}\right)-\left(v_{m}^{M}-v_{m}\right) \frac{\left(v_{m}^{M}+\lambda \Delta_{w}-v_{m}^{E}\right)\left(v_{m}^{L}-v_{m}^{M}-\lambda \Delta_{w}\right)}{\left(v_{m}^{M}+\lambda \Delta_{w}-v_{m}\right)\left(v_{m}^{L}-v_{m}^{E}\right)} \phi_{m}$.

Routine substitution then yields eq. (25). 


\subsection{Mean departure time of men}

The integral term in eq. (26) can be written:

$$
\int_{n=0}^{N} t_{m}^{d}(n) d n=N_{m E} \bar{t}_{m E}+N_{m L} \bar{t}_{m L},
$$

where $\bar{t}_{m E}$ is the average departure time of men who arrive early, and $\bar{t}_{m L}$ is the average departure time of men who arrive late. The departure rate is constant during the early arrival period, $\left[t_{0 m}^{M}, \tilde{t}_{m}^{M}\right)$, and constant during the late arrival period, $\left(\tilde{t}_{m}^{M}, t_{e m}^{M}\right]$. Therefore

$$
\bar{t}_{m E}=\frac{t_{0 m}^{M}+\tilde{t}_{m}^{M}}{2}
$$

and

$$
\bar{t}_{m L}=\frac{\tilde{t}_{m}^{M}+t_{e m}^{M}}{2} .
$$

$t_{0 m}^{M}$ and $t_{e m}^{M}$ are given by eqs. (21) and (22). Using the above equations it follows that

$$
\begin{gathered}
\int_{n=0}^{N} t_{m}^{d}(n) d n=t_{m}^{*} N+\frac{1}{2\left(v_{m}^{L}-v_{m}^{E}\right)} \cdot \\
{\left[2\left(v_{m}^{M}+\lambda \Delta_{w}\right)-v_{m}^{E}-v_{m}^{L}-\frac{\left(v_{m}^{M}+\lambda \Delta_{w}-v_{m}^{E}\right)\left(v_{m}^{L}-v_{m}^{M}-\lambda \Delta_{w}\right)}{v_{m}^{M}+\lambda \Delta_{w}-v_{m}}\right] \phi_{m} N,}
\end{gathered}
$$

which yields eq. (26) in the text.

\subsection{Condition for all women to benefit from cooperation}

All women benefit from cooperation if all men depart later in the cooperative equilibrium than the noncooperative equilibrium. The cooperative equilibrium begins later, but the departure rate is higher for both early and late arrival. It is therefore necessary to check whether the cumulative departures curve for the cooperative equilibrium catches up to the cumulative departures curve for the noncooperative equilibrium. At time $\tilde{t}_{m}^{M}$, a man arrives on time in the cooperative equilibrium. At this point $N_{m E}$ men have departed in the cooperative equilibrium. Let $\widehat{t}^{N}$ denote the time at which $N_{m E}$ have departed in the noncooperative equilibrium. If $\widehat{t}^{N}<\tilde{t}_{m}^{M}$, then all men depart earlier in the noncooperative equilibrium and all women are better off. Time $\widehat{t}^{N}$ is solved using the formula

$$
\widehat{t}^{N}=\left.t_{0 m}^{M}\right|_{\lambda>0}+\frac{\left.N_{m E}\right|_{\lambda>0}}{\left.r_{m E}^{N}\right|_{\lambda=0}}
$$

$t_{0 m}^{M}$ is given by eq. (21), $N_{m E}$ by eq. (49), and $r_{m E}^{N}$ by eq. (19) with $\lambda=0$. Making the substitutions one obtains

$$
\widehat{t}^{N}=t_{m}^{*}-\left(\frac{\left(v_{m}^{L}-v_{m}^{M}\right)\left(v_{m}^{M}-v_{m}^{E}\right)}{v_{m}^{M}-v_{m}}+\frac{v_{m}^{E}-v_{m}}{v_{m}^{M}-v_{m}} \lambda \Delta_{w}\right) \frac{\phi_{m}}{v_{m}^{L}-v_{m}^{E}}
$$


Given eqs. (56) and (51), the condition $\widehat{t}^{N}<\tilde{t}_{m}^{M}$ reduces to condition (42) in the text. 